\title{
A Novel Sensorless Support Vector Regression Based Multi-Stage Algorithm to Track the Maximum Power Point for Photovoltaic Systems
}

by

Ahmad Osman Khedr Ibrahim

\author{
A thesis \\ presented to the University of Waterloo \\ in fulfillment of the \\ thesis requirement for the degree of \\ Master of Applied Science \\ in \\ Electrical and Computer Engineering
}

Waterloo, Ontario, Canada, 2012

(CAhmad Osman Khedr Ibrahim 2012 


\section{AUTHOR'S DECLARATION}

I hereby declare that I am the sole author of this thesis. This is a true copy of the thesis, including any required final revisions, as accepted by my examiners.

I understand that my thesis may be made electronically available to the public. 


\begin{abstract}
Solar energy is the energy derived from the sun through the form of solar radiation. Solar powered electrical generation relies on photovoltaic (PV) systems and heat engines. These two technologies are widely used today to provide power to either standalone loads or for connection to the power system grid.

Maximum power point tracking (MPPT) is an essential part of a PV system. This is needed in order to extract maximum power output from a PV array under varying atmospheric conditions to maximize the return on initial investments. As such, many MPPT methods have been developed and implemented including perturb and observe $(\mathrm{P} \& \mathrm{O})$, incremental conductance (IC) and Neural Network (NN) based algorithms. Judging between these techniques is based on their speed of locating the maximum power point (MPP) of a PV array under given atmospheric conditions, besides the cost and complexity of implementing them. The P\&O and IC algorithms have a low implementation complexity but their tracking speed is sluggish. NN based techniques are faster than P\&O and IC. However, they may not provide the global optimal point since they are prone to multiple local minima. To overcome the demerits of the aforementioned methods, support vector regression (SVR) based strategies have been proposed for the estimation of solar irradiation (for MPPT). A significant advantage of SVR based strategies is that it can provide the global optimal point, unlike NN based methods. In the published literature of SVR based MPPT algorithms, however, researchers have assumed a constant temperature. The assumption is not plausible in practice as the temperature can vary significantly during the day. The temperature variation, in turn, can remarkably affect the effectiveness of the MPPT process; the inclusion of temperature measurements in the process will add to the cost and complexity of the overall PV system, and it will also reduce the reliability of the system.
\end{abstract}


The main goal of this thesis is to present a novel sensorless SVR based multi-stage algorithm (MSA) for MPPT in PV systems. The proposed algorithm avoids outdoor irradiation and temperature sensors. The proposed MSA consists of three stages: The first stage estimates the initial values of irradiation and temperature; the second stage instantaneously estimates the irradiation with the assumption that the temperature is constant over one-hour time intervals; the third stage updates the estimated value of the temperature once every one hour. After estimating the irradiation and temperature, the voltage corresponding to the MPP is estimated, as well. Then, the reference PV voltage is given to the power electronics interface. The proposed strategy is robust to rapid changes in solar irradiation and load, and it is also insensitive to ambient temperature variations. Simulations studies in PSCAD/EMTDC and Matlab demonstrate the effectiveness of the proposed technique. 


\section{Acknowledgements}

First and foremost, I thank God for helping me complete this work and reach this stage of life. Words are not enough to express my gratitude for all his blessings.

I would like to thank my supervisor, Dr. Otman Basir, for his support and guidance over the course of my research and for the discussions we had that helped bring out this work. I would also like to thank Dr. Mohamed-Yahia Dabbagh and Dr. Tarek EL-Fouly for taking the time to read my thesis.

My deepest gratitude goes to my family members, especially my mother and father for their patience and support. I thank all my brothers and sisters as well. 


\section{Dedication}

In memory of my grandparents 


\section{Table of Contents}

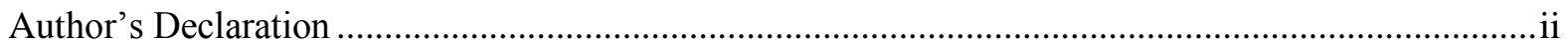

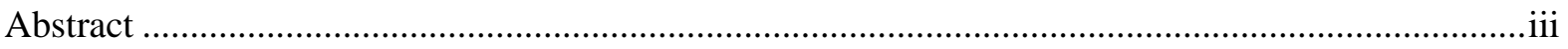

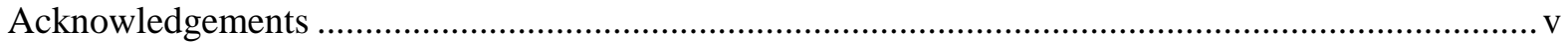

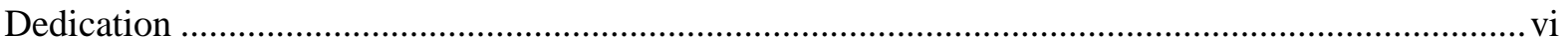

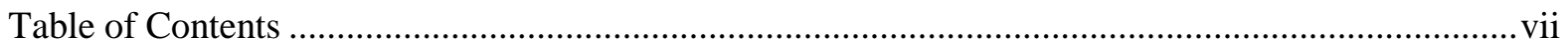

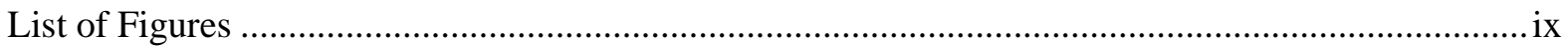

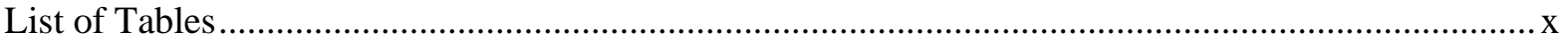

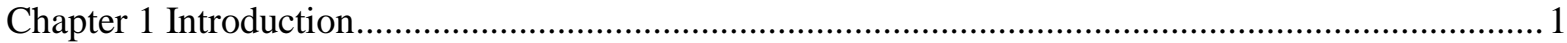

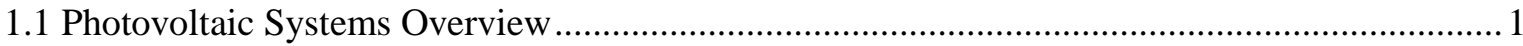

1.2 Maximum Power Point Tracking for Photovoltaic Systems ..................................................... 3

Chapter 2 Components of Grid-Connected Photovoltaic Systems ..................................................... 6

2.1 Photovoltaic Cell Technologies and Modeling .................................................................... 7

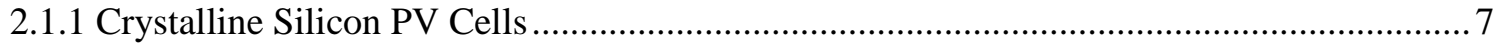

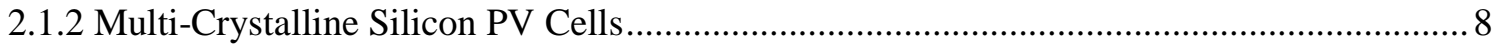

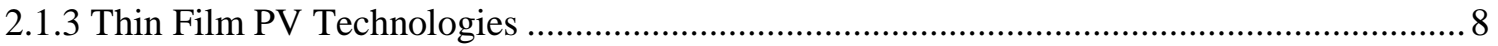

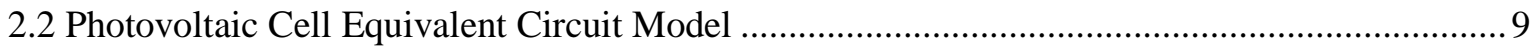

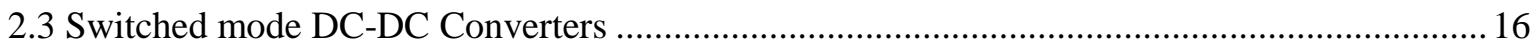

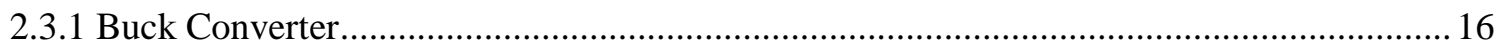

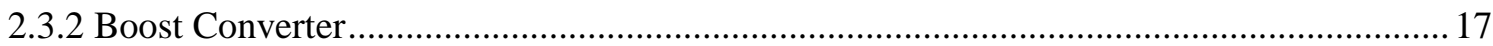

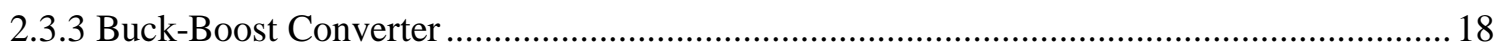

2.4 Three Phase Inverters (DC-AC Converters) …….................................................................. 18

2.5 Maximum Power Point Tracking (MPPT) Techniques ..........................................................20

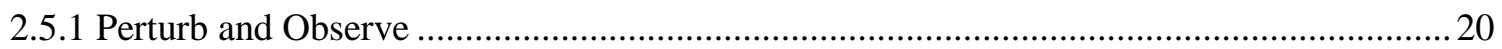

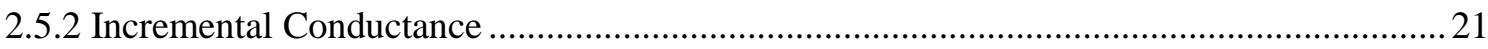

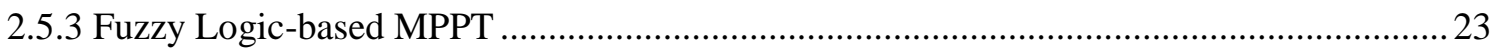

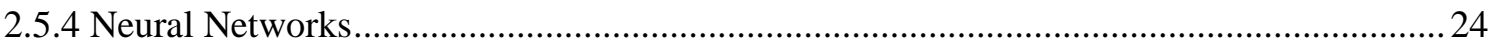

Chapter 3 Control of Three-Phase Grid Connected PV System...................................................... 26

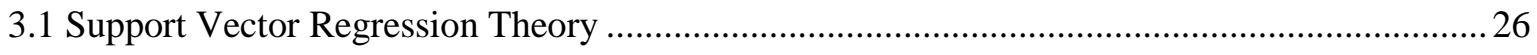

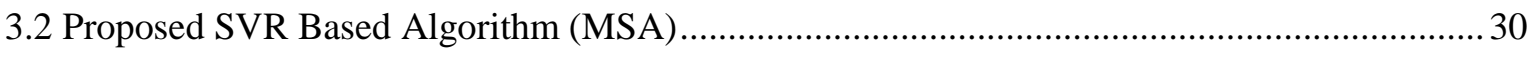

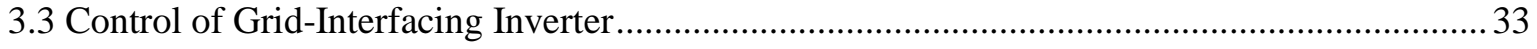

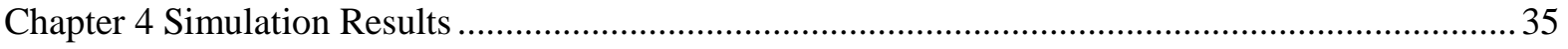

vii 
Chapter 5 Conclusion and Future Work

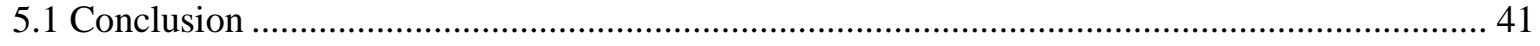

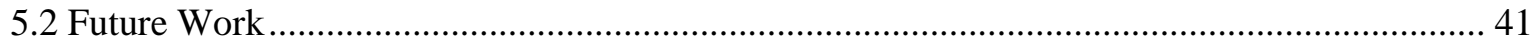

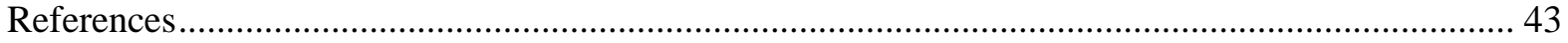

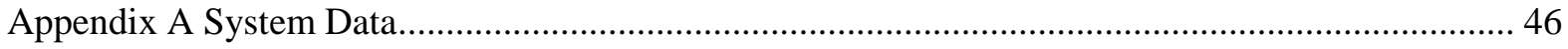




\section{List of Figures}

Fig. 1-1: Autonomous PV system with batteries ......................................................................... 1

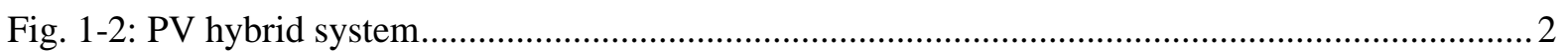

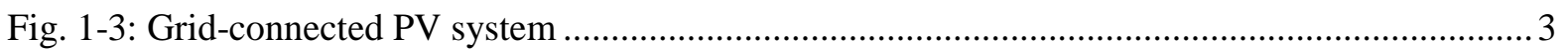

Fig. 1-4: Example for variations of daily air temperature at Waterloo, ON, Canada ............................ 4

Fig. 1-5: Example for variations of daily solar radiation at Waterloo, ON, Canada .............................5

Fig. 2-1: Components of a grid connected PV system ................................................................... 6

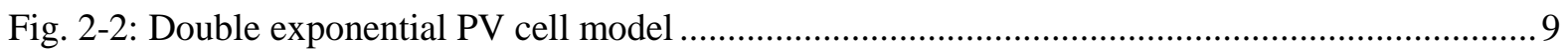

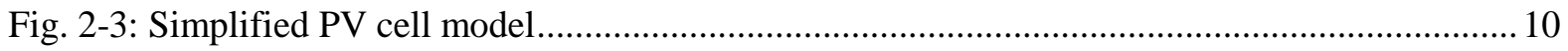

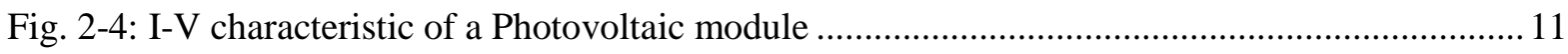

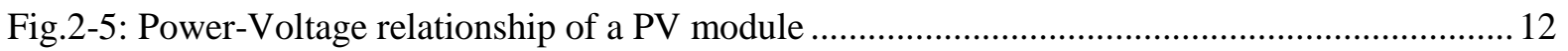

Fig. 2-6: I-V characteristics of the PV module under different solar irradiation levels ....................... 14

Fig. 2-7: P-V characteristics of the PV module under different solar irradiation levels ..................... 15

Fig. 2-8: I-V characteristics of the PV module at different surface temperatures .............................. 15

Fig. 2-9: P-V characteristics of the PV module at different surface temperatures .............................. 16

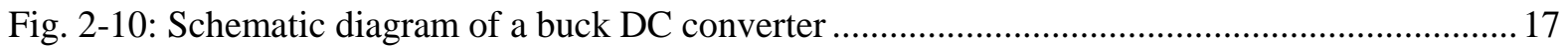

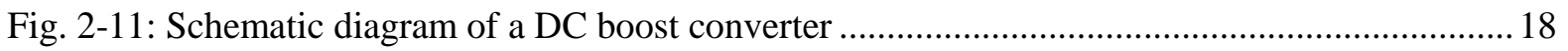

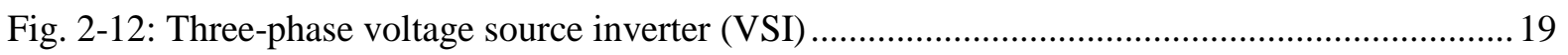

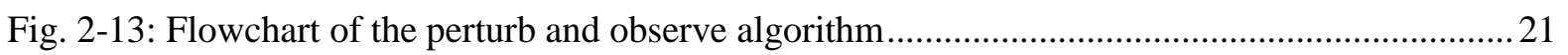

Fig. 2-14: Flowchart of the Incremental conductance MPPT algorithm .......................................... 22

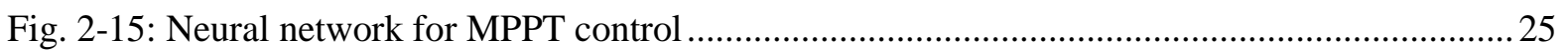

Fig.: 3-1 Data transformation from input space to kernel space ….................................................. 27

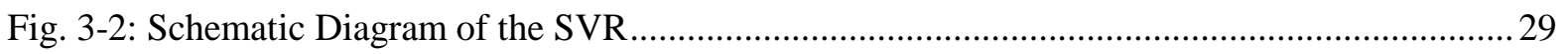

Fig. 3-3: I-V curves for PV under variable irradiation $(\mathrm{G})$ in $\mathrm{W} / \mathrm{m} 2$ and temperature $(\mathrm{T})$ in ${ }^{\circ} \mathrm{C}$......... 30

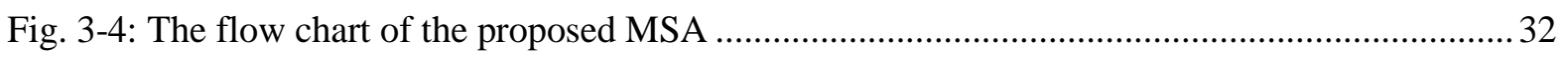

Fig. 3-5: The power and control circuit for the DC-DC boost converter ........................................... 33

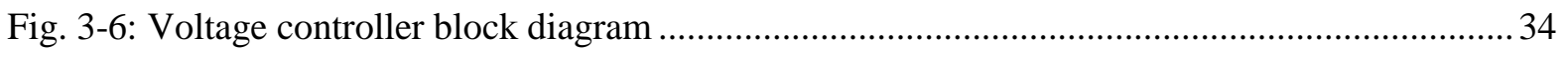

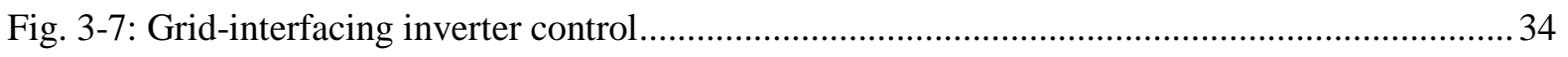

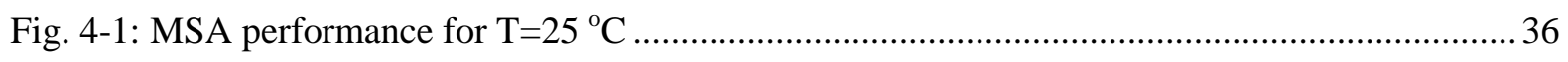

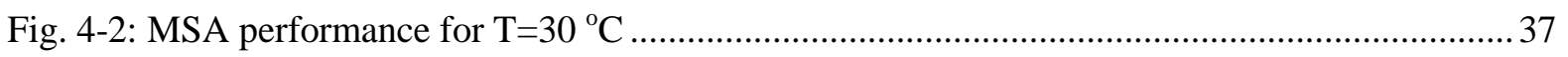

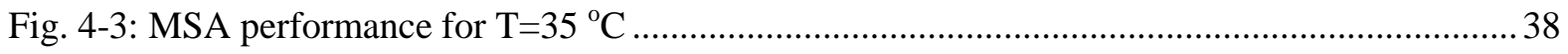

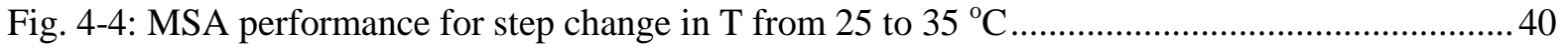




\section{List of Tables}

Table 2-1: Perturbation directions for the $\mathrm{P} \& \mathrm{O}$ algorithm based on output power variations ............ 21

Table 2-2: Rule based look-up table for fuzzy logic MPPT ......................................................... 24 


\section{Chapter 1}

\section{Introduction}

Photovoltaic (PV) systems are used to convert sunlight into electricity. They are a safe, reliable, low maintenance source of solar electricity that produces no on-site pollution or emissions. PV systems incur few operating costs and are easy to install on most homes.

\subsection{Photovoltaic Systems Overview}

PV systems are categorized into three types [1]: autonomous, hybrid and grid-connected. The type of the system will depend on needs, location and budget.

Autonomous, or stand-alone, systems are completely independent of other power sources. They are usually used to power remote homes, cottages or lodges as well as in applications such as remote monitoring and water pumping. In most cases, an autonomous system will require batteries for storage. Such systems are particularly useful and cost-effective for summer applications, when access to a site is difficult or costly, or when maintenance needs to be minimized.

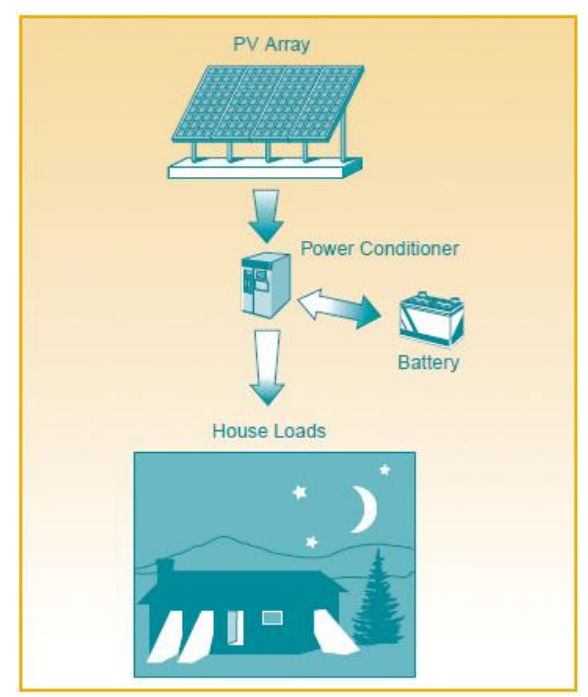

Fig. 1-1: Autonomous PV system with batteries [1]. 


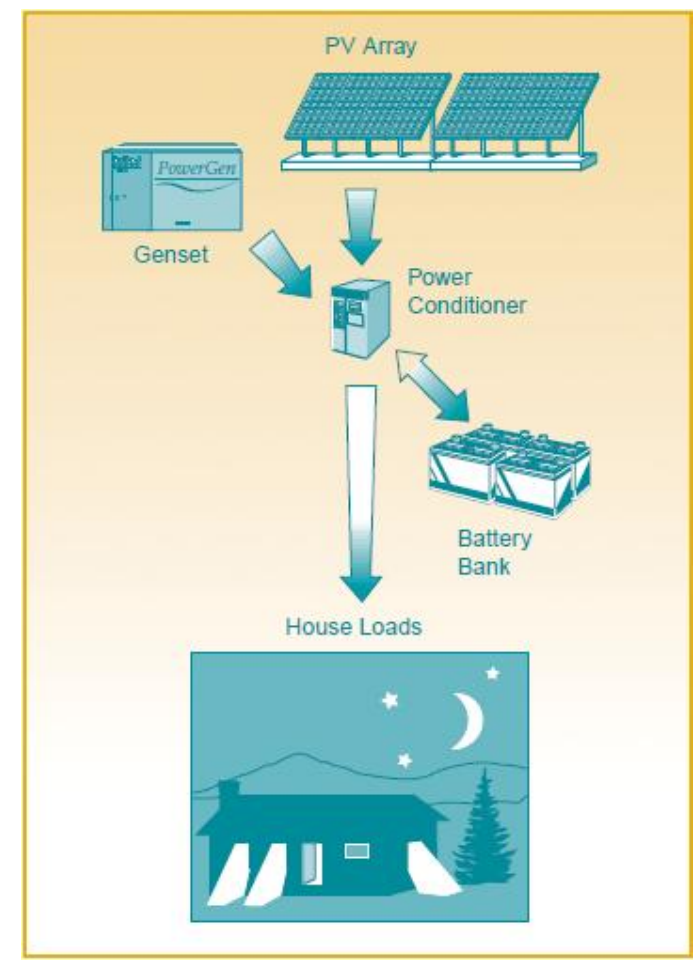

Fig. 1-2: PV hybrid system [1].

Hybrid systems receive a portion of their power from one or more additional sources. In practice, PV modules are often paired with a wind generator or a fuel-fired generator. Such systems usually require batteries for storage. They are most appropriate when energy demand is high (in the winter or year-round), when power must be available on demand, or if the budget is limited.

Grid-connected systems allow reducing consumption from the electricity grid and, in some instances, feeding the surplus energy back into the grid. In some cases, the utility may give credit for the energy returned to the grid. Since power is normally stored in the grid itself, batteries are not necessary unless some form of autonomous power is desirable during outages. These systems are used in buildings, homes or cottages already hooked up to the electrical grid. The main focus in this thesis will be on these grid-connected PV systems. 


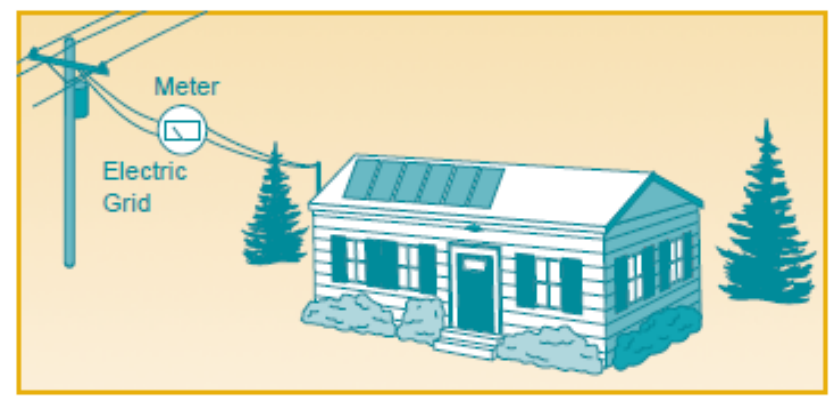

Fig. 1-3: Grid-connected PV system [1].

\subsection{Maximum Power Point Tracking for Photovoltaic Systems}

PV modules still suffers from relatively low energy conversion efficiencies. Hence, operating a PV system at its maximum power point is crucial. Therefore, many MPPT methods have been introduced in the literature. Perturb and observe is the most commonly used MPPT method due to its ease of implementation [2], [3]. However, one of the major drawbacks of the $\mathrm{P} \& \mathrm{O}$ method is that under steady state operation, the output power oscillates around the maximum power point. The Incremental Conductance technique was proposed to overcome the disadvantages of the $\mathrm{P} \& \mathrm{O}$ method [2]. This IC technique stops and determines when the MPP is reached without having to oscillate around this value. However, it can produce oscillations and can perform erratically under rapidly changing atmospheric conditions. Furthermore, the computational time is increased due to slowing down of the sampling frequency resulting from the higher complexity of the algorithm compared to the $\mathrm{P} \& \mathrm{O}$ method.

To overcome the demerits of the aforementioned methods, support vector regression based strategies have been proposed for the estimation of solar irradiation (for the MPPT) [4]. A significant advantage of SVR based method is that it can provide the global optimal point, unlike other methods, for example, artificial neural networks, which are prone to multiple local minima. In the published literature, however, researchers have assumed a constant temperature. The assumption is not plausible 
in practice as the temperature can vary significantly during the day. Fig. 1-4 and 1-5 show variations of the daily temperature and solar irradiation, respectively, at Waterloo city, Ontario, Canada. For each figure, the darker line shows the readings on 10-May-2011, and the lighter line shows the readings on 9-May-2011. The temperature variation, in turn, can remarkably affect the effectiveness of the MPPT process; the inclusion of temperature measurements in the process will add to the cost and complexity of the overall PV system.

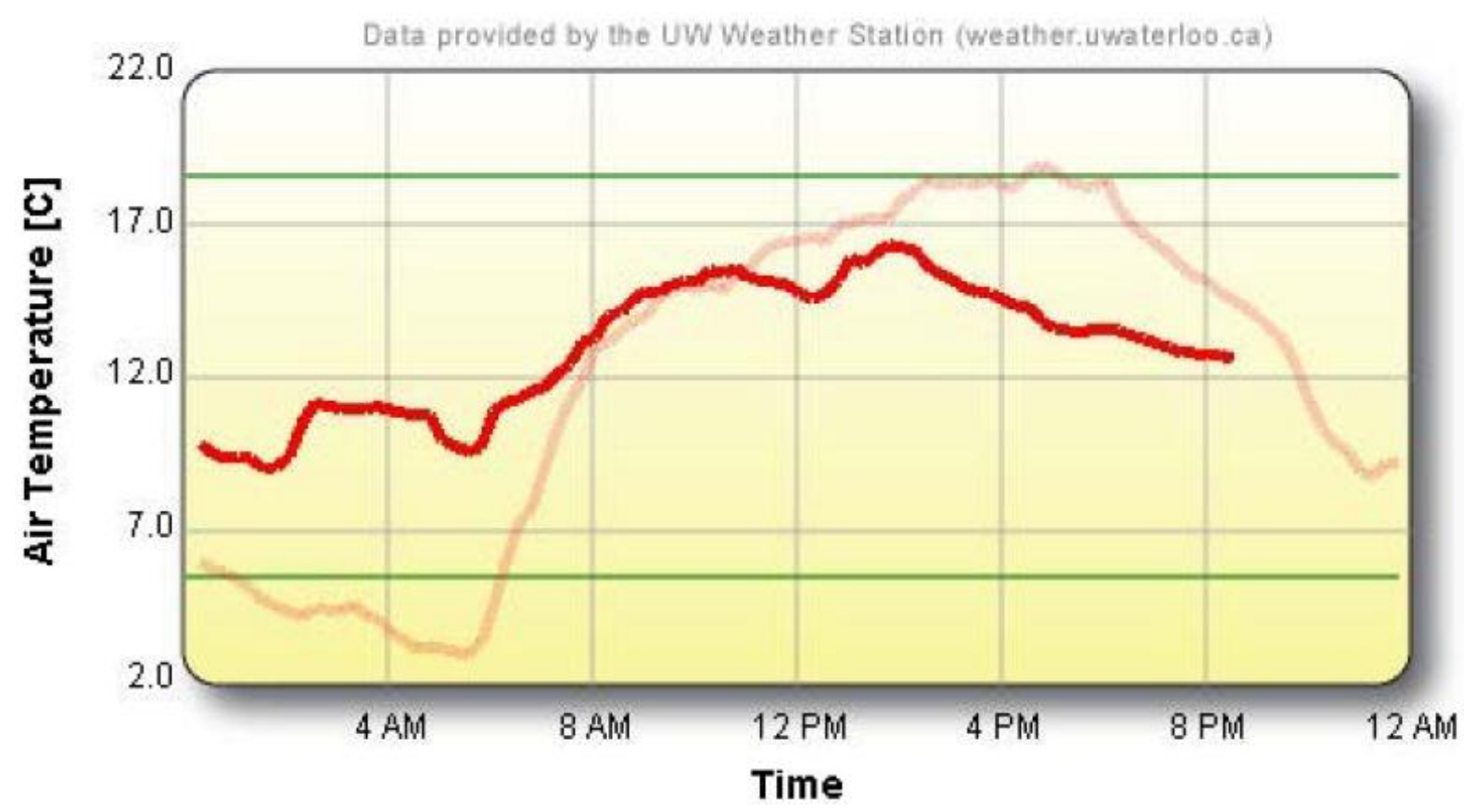

Fig. 1-4: Example for variations of daily air temperature at Waterloo, ON, Canada. 


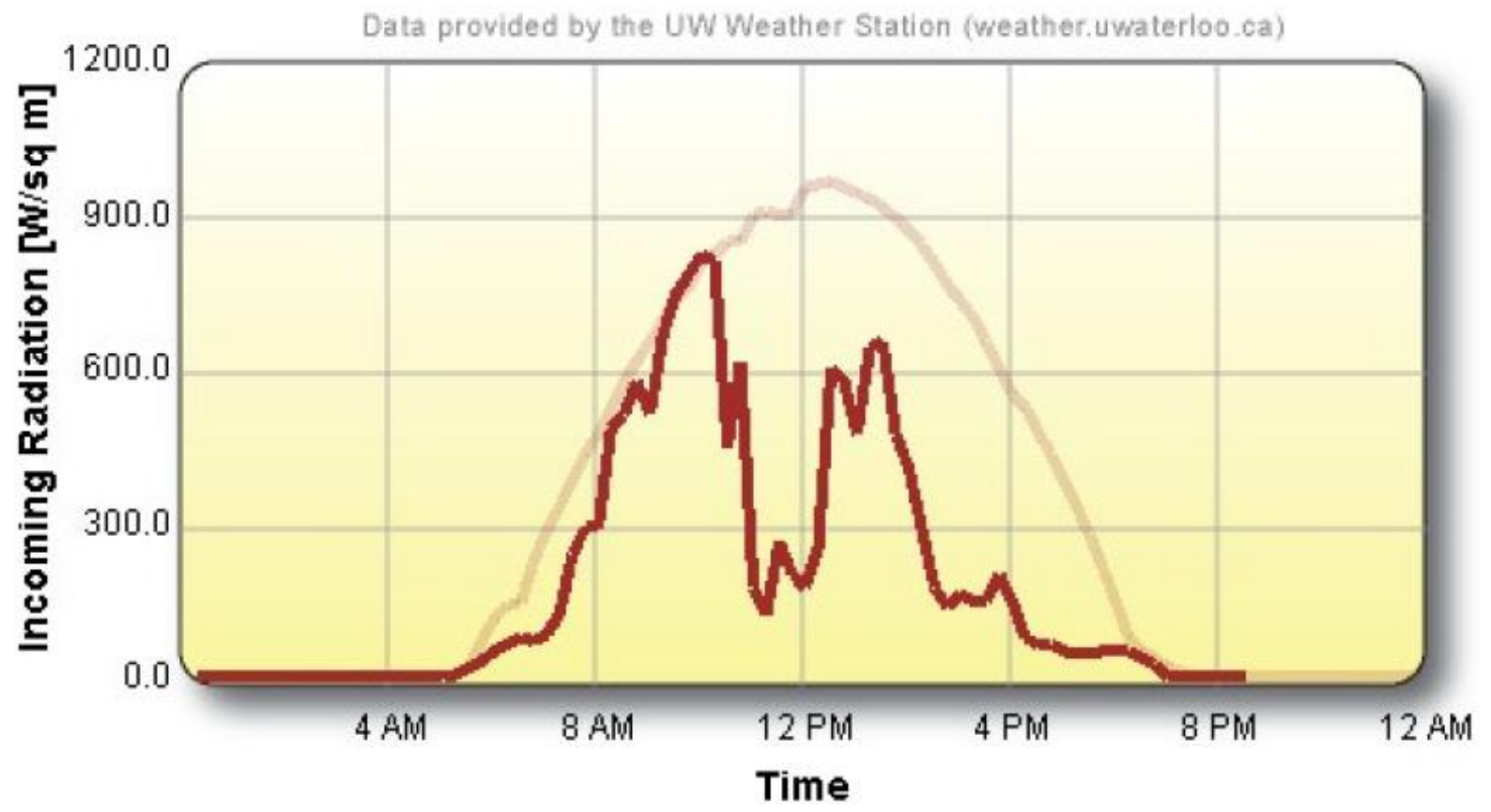

Fig. 1-5: Example for variations of daily solar radiation at Waterloo, $\mathrm{ON}$, Canada.

This thesis proposes a novel multi-stage algorithm for MPPT in PV systems. The proposed algorithm avoids outdoor irradiation and temperature sensors. The proposed MSA consists of three stages: The first stage estimates the initial values of irradiation and temperature; the second stage instantaneously estimates the irradiation with the assumption that the temperature is constant over one-hour time intervals; the third stage updates the estimated value of the temperature once every one hour. After estimating the irradiation and temperature, the voltage corresponding to the MPP is estimated, as well. Then, the reference PV voltage is given to the power electronics interface. The proposed strategy is robust to rapid changes in solar irradiation and load, and it is also insensitive to ambient temperature variations. Simulations studies in PSCAD/EMTDC and Matlab demonstrate the effectiveness of the proposed technique. 


\section{Chapter 2 \\ Components of Grid-Connected Photovoltaic Systems}

The aim of this chapter is to present a summary of the most important building blocks in a grid connected PV system.

Numerous components are needed to build a grid connected PV system to carry out the power generation and conversion functions, as shown in figure 2-1. A PV array converts the light from the sun into DC current. A DC-DC converter is connected to the PV array to control its terminal voltage and to provide the means to implement an MPPT method. The output power of the array is stored temporarily in large DC link capacitors to hold the power. A three-phase inverter is then connected to the DC link capacitors to achieve the power conversion of the array DC output power into AC power suitable for injection into the grid. The technique of space vector pulse width modulation (SVPWM) is adopted to control the magnitude and phase of the inverter output voltage. A harmonics filter is located after the inverter to reduce the harmonics in the output current which result from the power conversion process. An interfacing transformer is connected after the filter to step up the output AC voltage of the inverter to match the grid voltage level. Protection relays and circuit breakers are used to isolate the PV system when faults occur to prevent damage to the equipment if their ratings are exceeded.

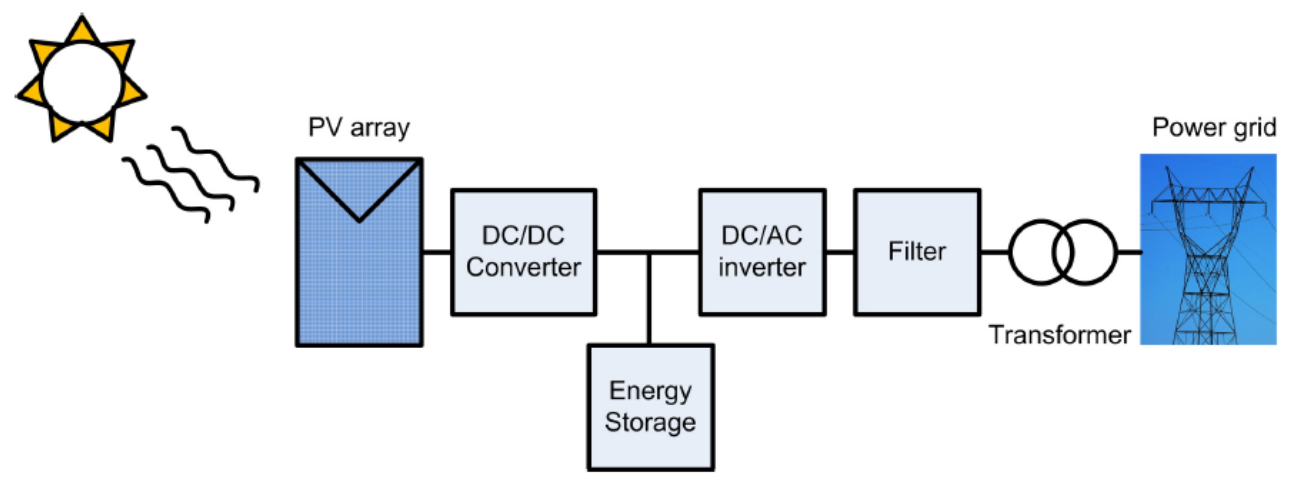

Fig. 2-1: Components of a grid connected PV system. 


\subsection{Photovoltaic Cell Technologies and Modeling}

PV cells are classified based on the sort of materials used in manufacturing them. Below are some of the common materials used to construct PV cells.

\subsubsection{Crystalline Silicon PV Cells}

Comprising $20 \%$ of the earth's crust composition, Silicon is considered the second most abundant element on earth [5]. Silicon exists in nature in the form of Silicon dioxide minerals like quartz and silicate based minerals. It has first to reach a high degree of purity before it can be used for manufacturing single crystal PV cells. High grade quartz or silicates are first treated chemically to form an intermediate silicon compound (Liquid trichlorosilane $\mathrm{SiHCl} 3$ ), which is then reduced in a reaction with hydrogen to produce chunks of highly pure Silicon, about $99.9999 \%$ in purity. After that, these chunks of silicon are melted and formed into a single large crystal of Silicon through a process called the Czochralski process. The large Silicon crystal is then cut into thin wafers using special cutting equipment. These wafers are then polished and doped with impurities to form the required p-n junction of the PV cell. Antireflective coating materials are added on top of the cell to reduce light reflections and allow the cell to better absorb sunlight. A grid of contacts made of silver or aluminum is added to the cell to extract the electric current generated when it is exposed to light. The experimental efficiency of Single crystal silicon cells is about $25 \%$ or slightly higher under standard test conditions $\left(1000 \mathrm{~W} / \mathrm{m} 2\right.$ and $\left.25^{\circ} \mathrm{C}\right)$. However, commercial PV modules' efficiency is in the range of $12 \%-15 \%$ [6]. The process of producing PV cells using this technology is quite expensive, which led to development of new technologies that do not suffer from this drawback. 


\subsubsection{Multi-Crystalline Silicon PV Cells}

In order to avoid the high cost of producing single crystal solar cells, cheaper multi-crystalline cells were developed. As the name implies, multi-crystalline Silicon solar cells do not have a single crystal structure. They are rather derived from several smaller crystals that together from the cell. The grain boundaries between each crystal reduce the net electric current that can be generated because of electron recombination with defective atomic bonds. However, the cost of manufacturing cells using this technology is less than what would be in the case of a single crystalline cell. The efficiency of modules produced using this technology ranges from $11 \%-14 \%$ [6].

\subsubsection{Thin Film PV Technologies}

Thin film PV cells are manufactured through the deposition of several thin layers of atoms or molecules of certain materials on a holding surface. They have the advantage over their crystalline Silicon counterparts in their thickness and weight. They can be 1 to 10 micrometers thin as compared to 300 micrometers for Silicon cells [7]. Another advantage is that they can be manufactured using an automated large area process that further reduces their cost. Thin film PV cells do not employ the metal grid required for carrying current outside the cell. However, they make use of a thin layer of conducting oxides to carry the output current to the external circuit. The electric field in the p-n junction of the cell is created between the surface contacts of two different materials, creating what is called a heterojunction PV cell. Thin film PV can be integrated on windows and facades of buildings because they generate electricity while allowing some light to pass through. Two common thin film materials are Copper indium diselenide (CIS for short) and Cadmium Telluride (CdTe). CIS thin films are characterized by their very high absorptivity. PV cells that are built from this material are of the heterojunction type. The top layer can be cadmium sulfide, while the bottom layer can be gallium to improve the efficiency of the device. Cadmium Telluride PV cells are similar to CIS in their construction and manufacturing process. However, the resistivity of p-type CdTe is quite high 
therefore increasing the internal losses. This issue can be addressed through the use of intrinsic CdTe while using a layer of zinc telluride between the cell and the back contacts. Efficiency for these technologies is about $10-13 \%$ [8].

\subsection{Photovoltaic Cell Equivalent Circuit Model}

The equivalent circuit model of a PV cell is required in order to simulate its real performance. One of the models proposed in literature is the double exponential model [6] shown in figure 2-2. Using the physics of p-n junctions, a cell can be modeled as a DC current source in parallel with two diodes that represent currents escaping due to diffusion and charge recombination mechanisms. Two resistances, $R_{s}$ and $R_{p}$, are included to model the contact resistances and the internal PV cell resistance respectively. The values of these two resistances can be obtained from measurements or by using curve fitting methods based on the $I-V$ characteristic of the cell. The work done in [9] is an example of using curve fitting techniques to approximate the values of $R_{s}$ and $R_{p}$.

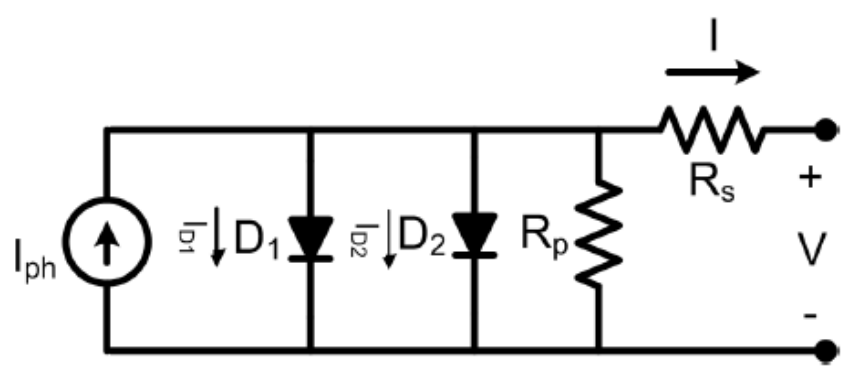

Fig. 2-2: Double exponential PV cell model. 
The relationship between the PV cell output current and terminal voltage is governed by:

$$
\begin{aligned}
& I=I_{p h}-I_{D 1}-I_{D 2}-\frac{V+I R_{s}}{R_{p}} \\
& I_{D 1}=I_{01}\left[\exp \left(\frac{q\left(V+I R_{s}\right)}{a k T}\right)-1\right] \\
& I_{D 2}=I_{02}\left[\exp \left(\frac{q\left(V+I R_{s}\right)}{a k T}\right)-1\right]
\end{aligned}
$$

where $I_{p h}$ is the PV cell internal generated photocurrent, $I_{D 1}$ and $I_{D 2}$ are the currents passing through diodes $\mathrm{D}_{1}$ and $\mathrm{D}_{2}, a$ is the diode ideality factor, $k$ is the Boltzmann constant $\left(1.3806503 \times 10^{-23} \mathrm{~J} / \mathrm{K}\right)$, $T$ is the cell temperature in degrees Kelvin, $q$ is the electron charge $\left(1.60217646 \times 10^{-19} \mathrm{C}\right), I_{01}$ and $I_{02}$ are the reverse saturation currents of each diode respectively.

Assuming that the current passing in diode $\mathrm{D}_{2}$ due to charge recombination is small enough to be ignored, a simplified PV cell model can be reached as shown in figure 2-3.

This model provides a good compromise between accuracy and model complexity and has been used in several previous works [10], [11] and [12]. In this case, current $I_{D 2}$ can be omitted from (2.1) and the relation simplifies to:

$$
I=I_{p h}-I_{0}\left[\exp \left(\frac{q\left(V+I R_{s}\right)}{a k T}\right)-1\right]-\frac{V+I R_{s}}{R_{p}}
$$

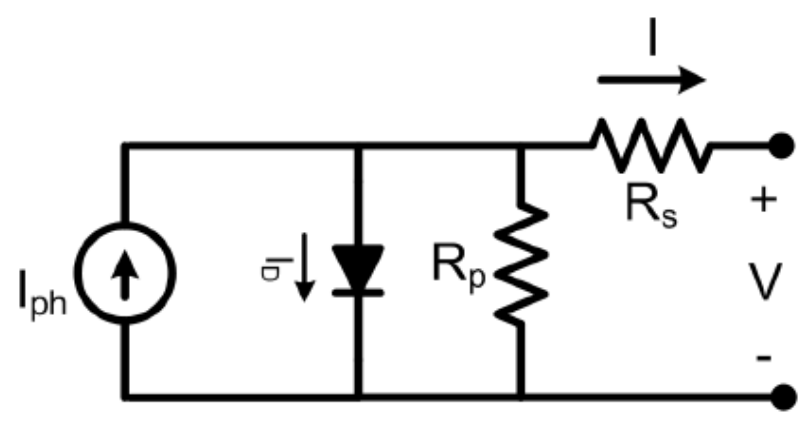

Fig. 2-3: Simplified PV cell model. 
It is obvious that the relationship between the PV cell terminal voltage and output current is nonlinear because of the existence of the exponential term in 2.1 and 2.2. The presence of the p-n semiconductor junction is the cause behind this nonlinearity. The result is a unique $I-V$ characteristic for the cell where the current output is constant over a wide range of voltages until it reaches a certain point where it starts dropping exponentially. $I-V$ characteristic of a $200 \mathrm{~W}$ PV module by Kyocera is shown in figure 2-4. A PV module is the outcome of connecting several PV cells in series to order to raise the output voltage. The characteristic has the same shape except for changes in the magnitude of the open circuit voltage.

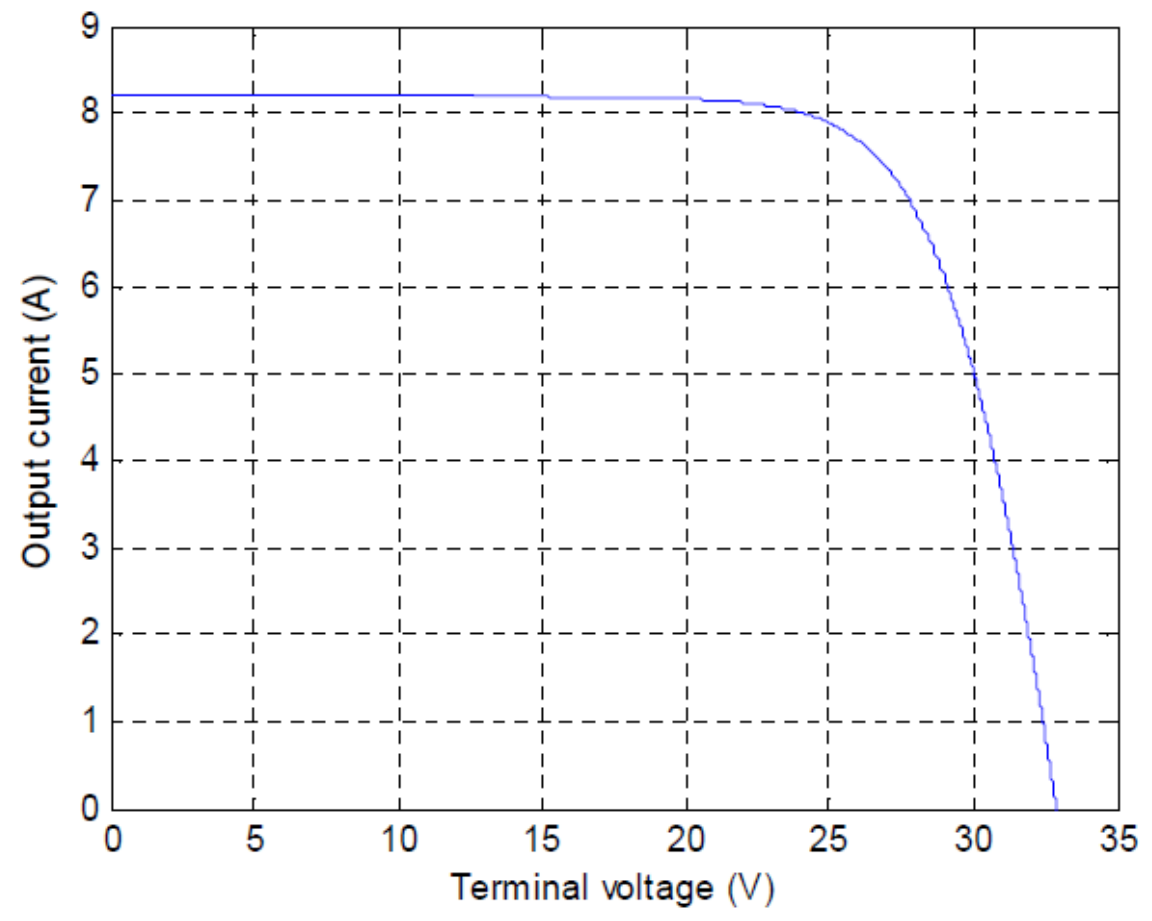

Fig. 2-4: I-V characteristic of a Photovoltaic module. 
Another important relationship in PV cells is the power-voltage characteristic. The product of multiplying the current and voltage is evaluated at each point in the curve to find out how much power can be obtained as voltage changes. The power-voltage relationship for the PV module is depicted in figure 2-5. Initially, power starts increasing as voltage increases. A certain point in the curve is reached where maximum power output can be obtained; this point is therefore referred to as the Maximum Power Point. After this point, power starts dropping as the terminal voltage increases until it finally reaches zero at open circuit voltage. Power output from a PV cell is dictated by the magnitude of the load resistance, defined by the division of the cell voltage overcurrent, in case of fixed loads. If the load impedance does not equal the value required to extract maximum power, then it is possible to use a switched mode DC converter to do the matching between the PV cell and the load. The process of changing the PV array terminal voltage externally to extract maximum power for different loads is known as Maximum Power Point Tracking (MPPT). Several techniques can be used to perform this task as will be explained in a following section of the thesis.

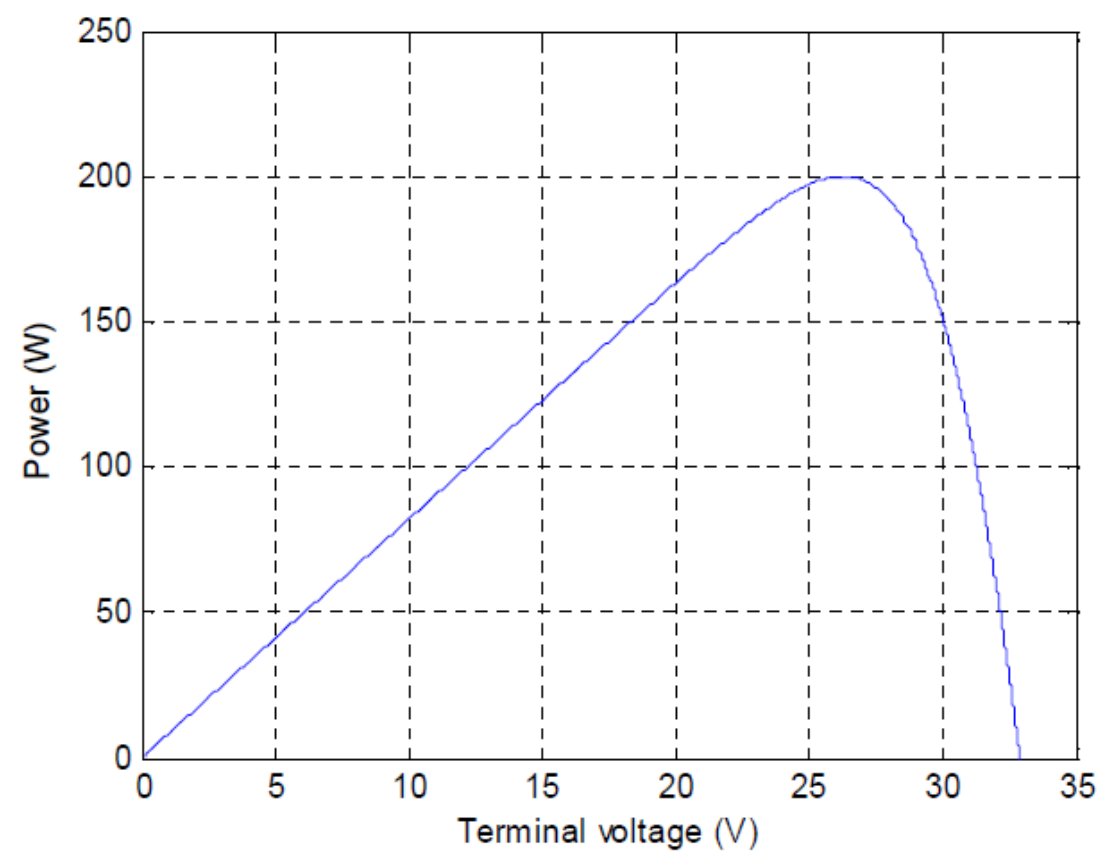

Fig.2-5: Power-Voltage relationship of a PV module. 
The PV cell characteristics also depend on external factors including temperature and solar irradiation level. To incorporate these effects into the model, two additional relations are used. Output current varies with solar irradiation and temperature through:

$$
I=\left(I_{n}+K_{I} \Delta T\right) \frac{G}{G_{n}}
$$

where $I_{n}$ is the nominal PV cell output current (at $25{ }^{\circ} \mathrm{C}$ and $1000 \mathrm{~W} / \mathrm{m}^{2}$ ), $K_{I}$ is the current/temperature variation coefficient $\left(\mathrm{A} /{ }^{\circ} \mathrm{C}\right), \Delta T$ is the variation from the nominal temperature $\left(25^{\circ} \mathrm{C}\right)$ and $G_{n}$ is the nominal solar irradiation $\left(1000 \mathrm{~W} / \mathrm{m}^{2}\right)$. The value of $K_{I}$ is relatively small and this makes the cell output current linearly dependent on solar radiation level more than temperature.

Temperature, however, has a strong effect on the reverse saturation current, $I_{0}$ in 2.2. The following relation can be used to model that effect [9]:

$$
I_{0}=\frac{I_{s c, n}+K_{I} \Delta T}{\exp \left(q\left(V_{o c, n}+K_{V} \Delta I\right) / a K T\right)-1}
$$

where $I_{s c, n}$ is the nominal short circuit current of the PV cell, $V_{o c, n}$ is the nominal open circuit voltage, $K_{I}$ and $K_{V}$ are the current and voltage temperature variation coefficients, in $\mathrm{A} /{ }^{\circ} \mathrm{C}$ and $\mathrm{V} /{ }^{\circ} \mathrm{C}$, respectively.

The effect of solar irradiation and temperature on the characteristics of the PV module is depicted in figures 2-6, 2-7, 2-8 and 2-9. To investigate the effect of solar irradiation on the currents and voltages of the module, temperature was held constant at $25{ }^{\circ} \mathrm{C}$ and the resulting $I-V$ and $P-V$ characteristics were plotted. Figure 2-6 shows the $I-V$ characteristics of the module at different irradiation levels of 500, 800 and $1000 \mathrm{~W} / \mathrm{m} 2$. The $P-V$ characteristics are shown in figure 2-7 for the same irradiation levels mentioned. It is noticed that output current is directly proportional to changes in solar irradiation as expected from the model. Maximum output power of the module is reduced by half when the solar irradiation drops to $500 \mathrm{~W} / \mathrm{m} 2$. However, the open circuit voltage does not change 
significantly. To find out the effect of temperature on the module performance, solar irradiation level was assumed constant at $1000 \mathrm{~W} / \mathrm{m} 2$ while allowing temperature to vary between 25 and $80{ }^{\circ} \mathrm{C}$. The result is shown in figures 2-8 and 2-9 for the $I-V$ and $P-V$ characteristics as temperature was set to 25 , 60 and $80{ }^{\circ} \mathrm{C}$ respectively. The open circuit voltage of the module decreases as surface temperature increases. Current, on the other hand, increases slightly with temperature. The maximum power output of the module reduces as the surface temperature rises.

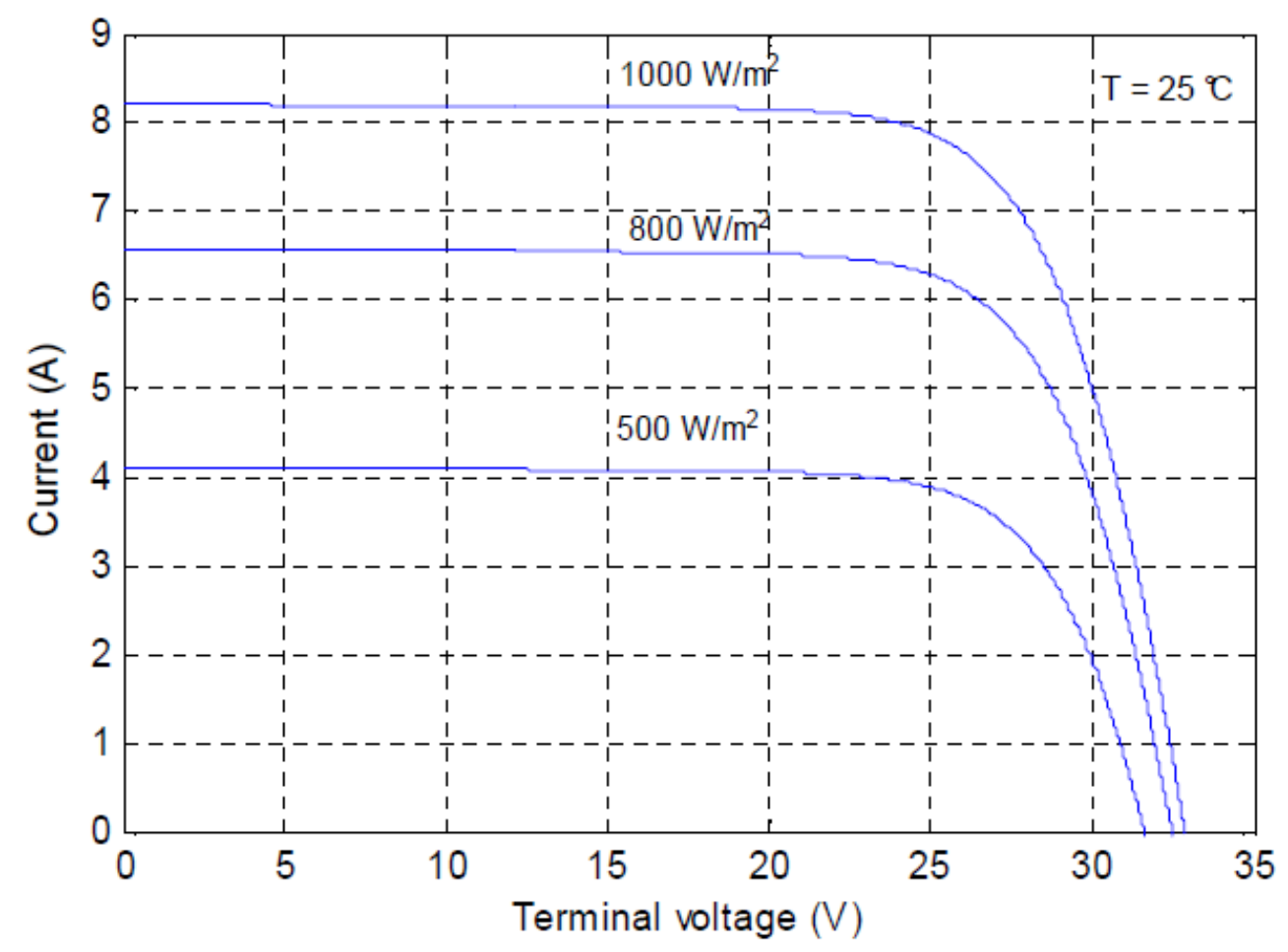

Fig. 2-6: I-V characteristics of the PV module under different solar irradiation levels. 


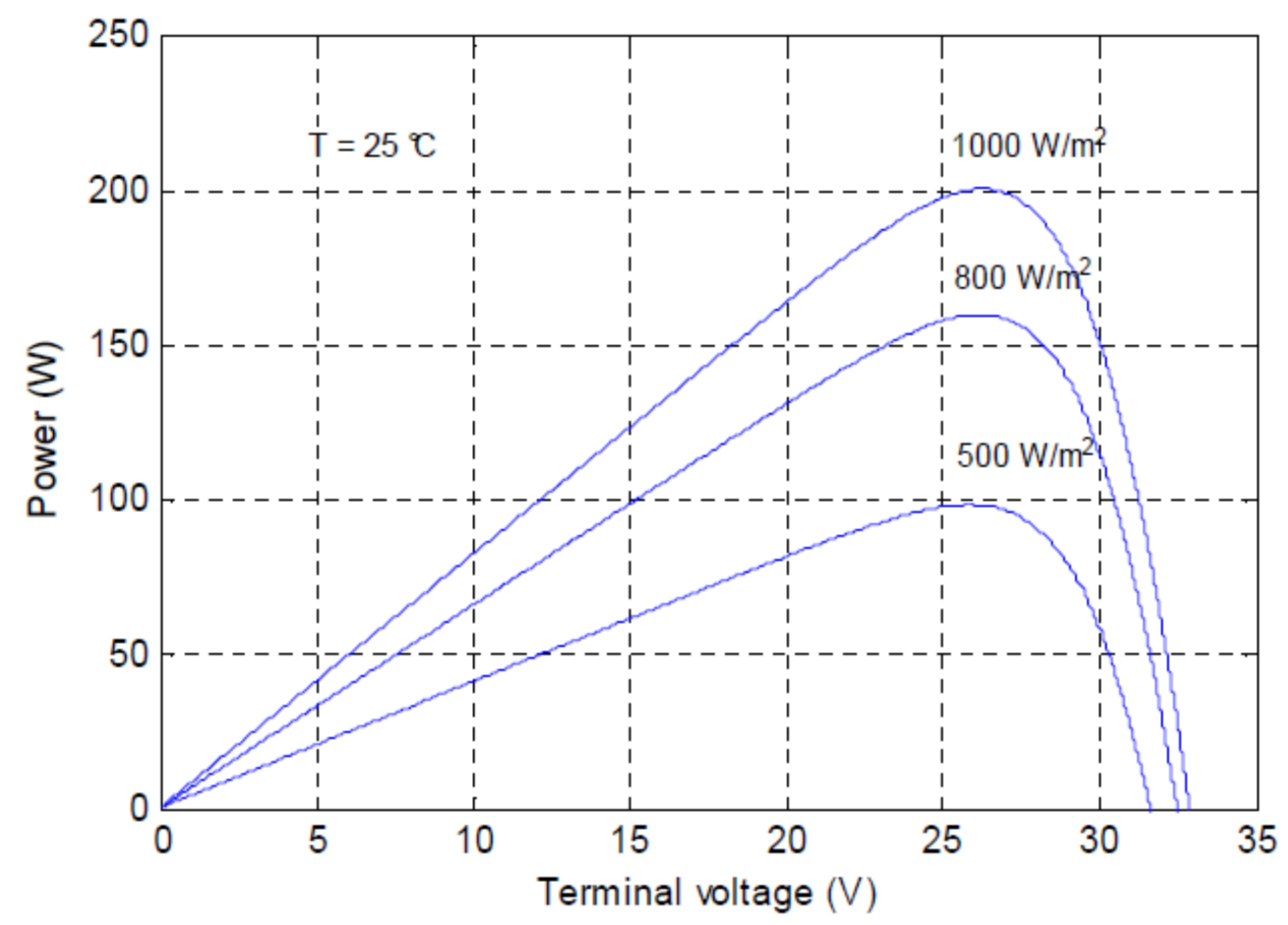

Fig. 2-7: $P-V$ characteristics of the $P V$ module under different solar irradiation levels.

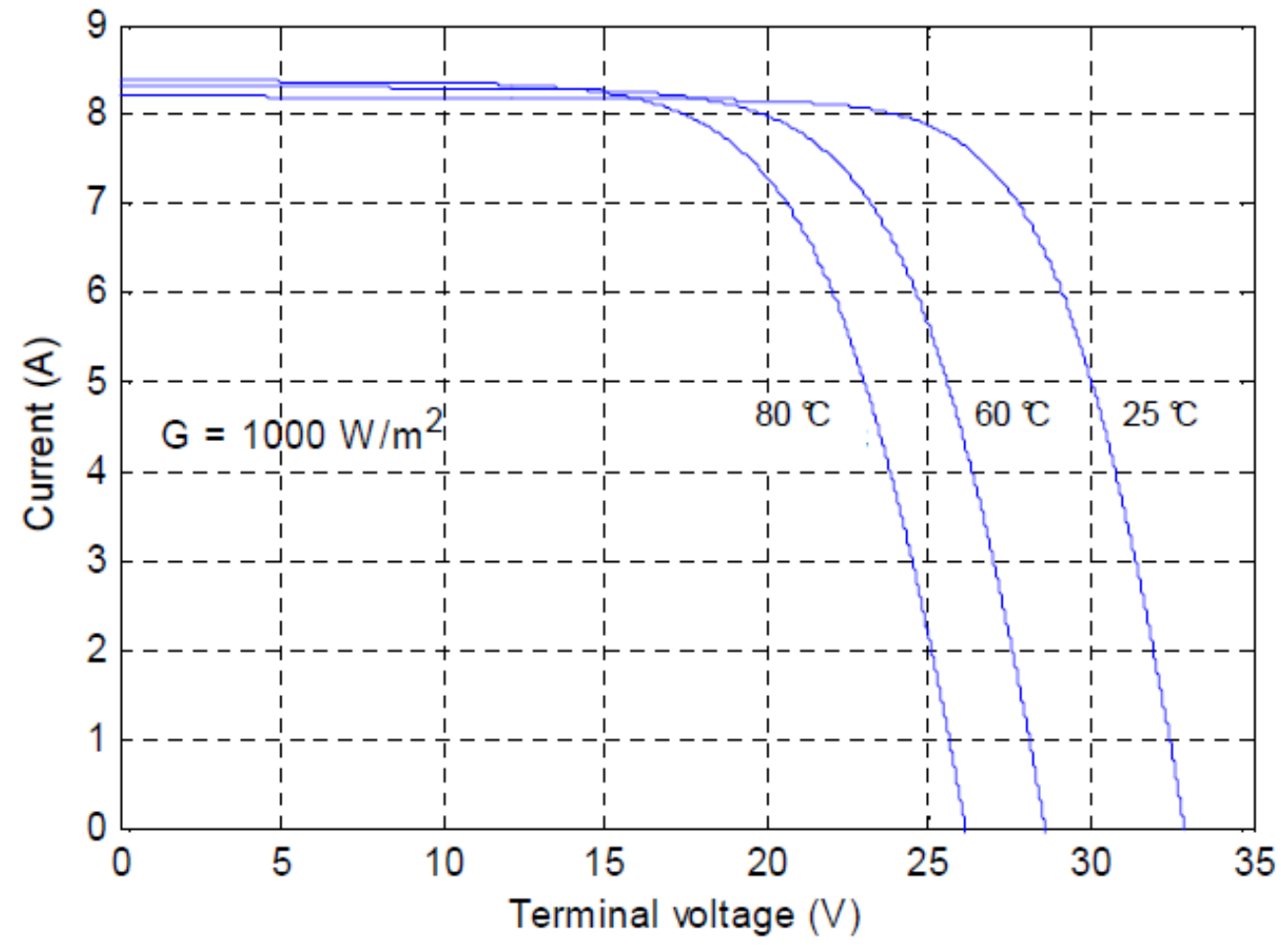

Fig. 2-8: I-V characteristics of the PV module at different surface temperatures. 


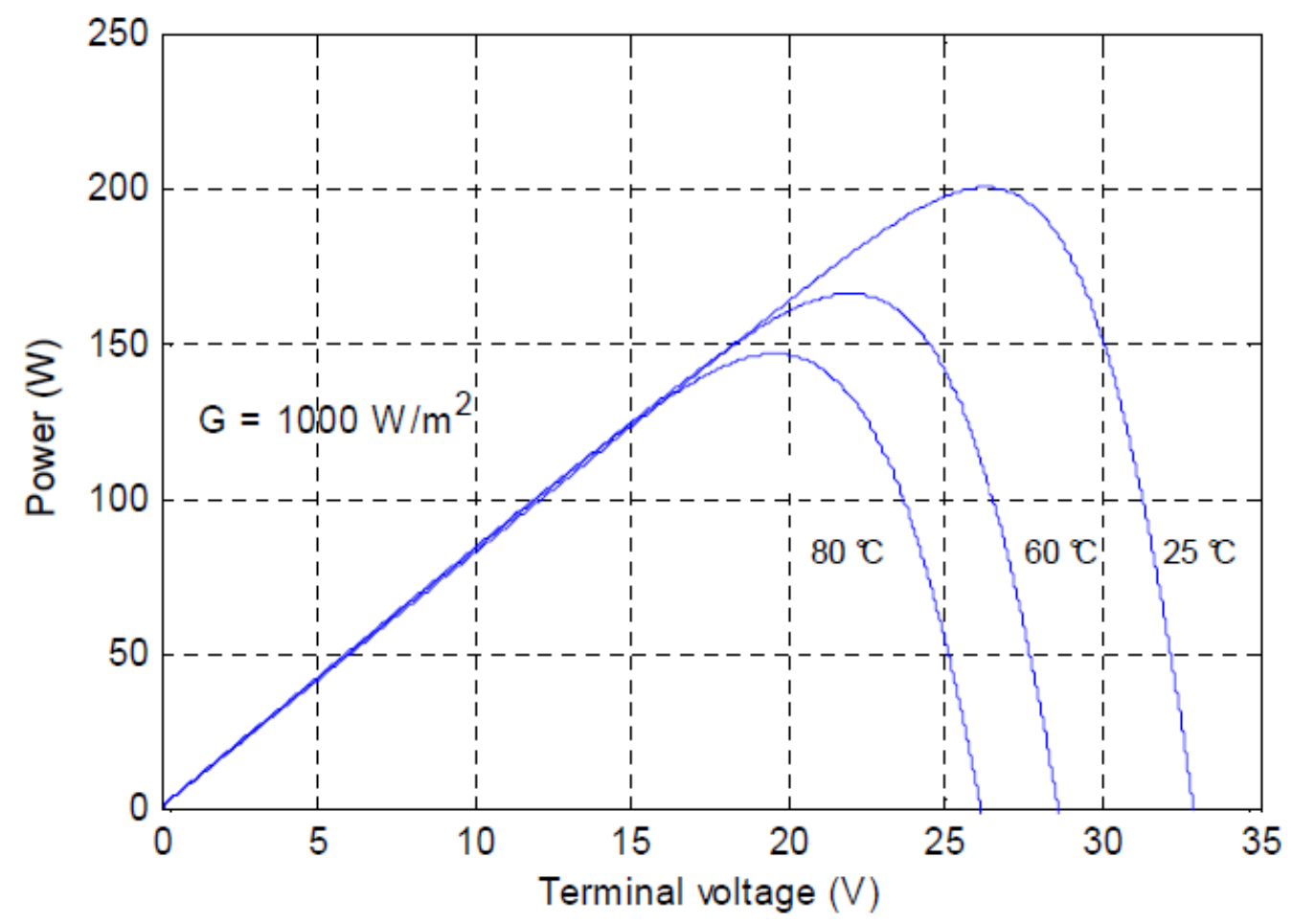

Fig. 2-9: P-V characteristics of the PV module at different surface temperatures.

\subsection{Switched Mode DC-DC Converters}

DC-DC converters are used in a wide variety of applications including power supplies, where the output voltage should be regulated at a constant value from a fluctuating power source, to reduce the ripples in the output voltage or achieve multiple voltage levels from the same input voltage. Several topologies exist to either increase or decrease the input voltage or perform both functions together using a single circuit. The three basic topologies of DC converters are: buck (step down), boost (step up) and the buck-boost converter topologies.

\subsubsection{Buck Converter}

The schematic diagram of a buck DC converter is shown in figure 2-10. It is composed of two main parts: a DC chopper and an output $L C$ filter to reduce the ripples in the resulting output. The output voltage of the converter is less than the input as determined by the duration the semiconductor switch 


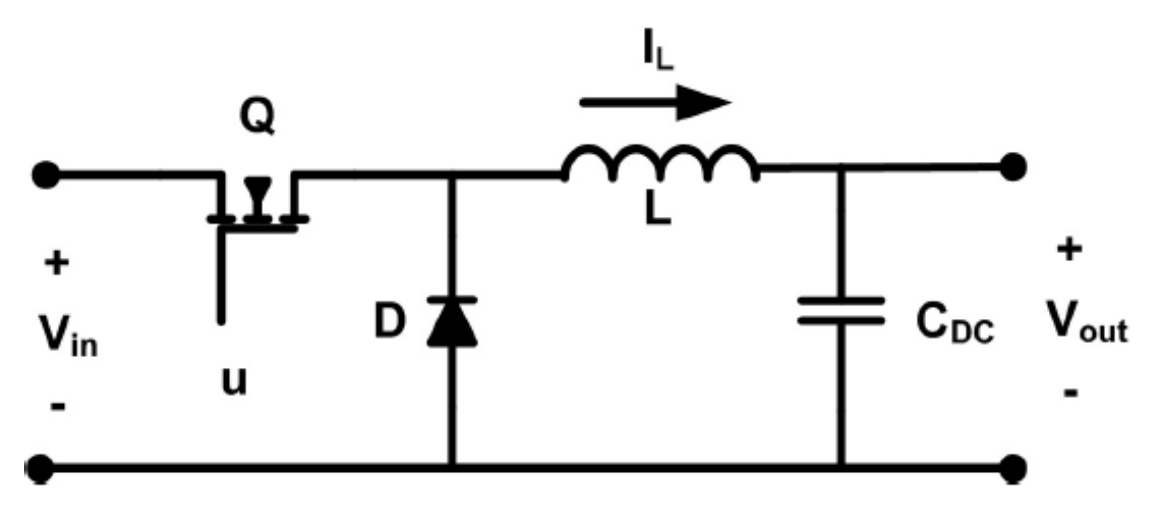

Fig. 2-10: Schematic diagram of a buck DC converter

$Q$ is closed. Under continuous conduction mode (CCM), the current $I_{L}$ passing through the inductor does not reach zero. The time integral of the inductor voltage over one period in steady state is equal to zero. From that, the relation between the input and output voltages can be obtained:

$$
\begin{aligned}
& \left(V_{\text {in }}-V_{\text {out }}\right) t_{\text {on }}-V_{\text {out }} t_{\text {off }}=0 \\
& \frac{V_{\text {out }}}{V_{\text {in }}}=\frac{t_{\text {on }}}{t_{\text {on }}+t_{\text {off }}} \quad \text { whered }=\text { dutycycle }
\end{aligned}
$$

\subsubsection{Boost Converter}

The boost DC converter is used to step up the input voltage by storing energy in an inductor for a certain time period, and then uses this energy to boost the input voltage to a higher value. The circuit diagram for a boost converter is shown in figure 2-11. When switch $Q$ is closed, the input source charges up the inductor while diode $D$ is reverse biased to provide isolation between the input and the output of the converter. When the switch is opened, energy stored in the inductor and the power supply is transferred to the load. The relationship between the input and output voltages is given by:

$$
\begin{aligned}
& V_{\text {in }} t_{\text {on }}+\left(V_{\text {in }}-V_{\text {out }}\right) t_{\text {off }}=0 \\
& \frac{V_{\text {out }}}{V_{\text {in }}}=\frac{t_{\text {on }}+t_{\text {off }}}{t_{\text {off }}}=\frac{1}{1-d}
\end{aligned}
$$




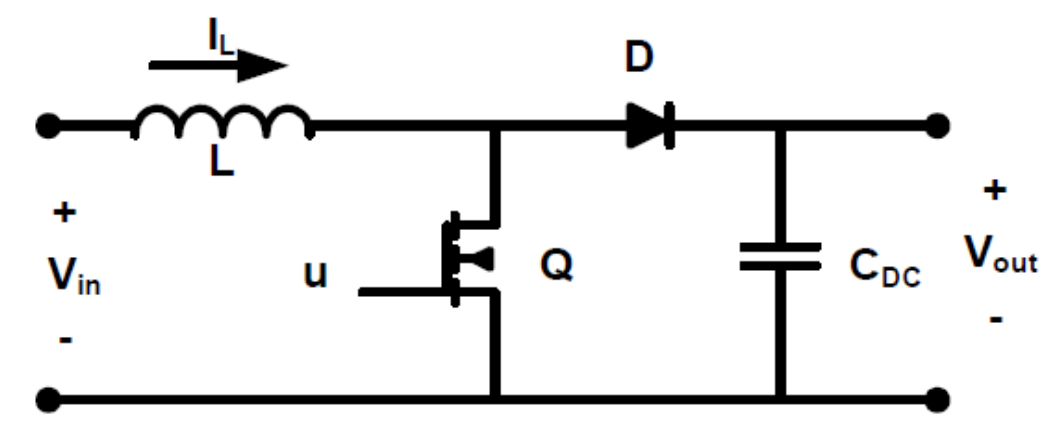

Fig. 2-11: Schematic diagram of a DC boost converter.

\subsubsection{Buck-Boost Converter}

This converter topology can be used to perform both functions of stepping the input voltage up or down, but the polarity of the output voltage is opposite to that of the input. The input and output voltages of this configuration are related through:

$$
\begin{aligned}
& V_{\text {in }} t_{\text {on }}+V_{\text {out }} t_{\text {off }}=0 \\
& \frac{V_{\text {out }}}{V_{\text {in }}}=\frac{-t_{\text {on }}}{t_{\text {off }}}=\frac{-d}{1-d}
\end{aligned}
$$

\subsection{Three Phase Inverters (DC-AC Converters)}

Voltage source inverters (VSI) are mainly used to convert a constant DC voltage into 3-phase AC voltages with variable magnitude and frequency. Figure 2-12 shows a schematic diagram of a 3 phase VSI. The inverter is composed of six switches S1 through S6 with each phase output connected to the middle of each "inverter leg". Two switches in each phase are used to construct one leg. The AC output voltage from the inverter is obtained by controlling the semiconductor switches ON and OFF to generate the desired output. Pulse width modulation (PWM) techniques are widely used to perform this task. In the simplest form, three reference signals are compared to a high frequency carrier waveform. The result of that comparison in each leg is used to turn the switches ON or OFF. This technique is referred to as sinusoidal pulse width modulation (SPWM). It should be noted that the 
switches in each leg should be operated interchangeably, in order not to cause a short circuit of the DC supply.

Insulated Gate Bipolar Transistors (IGBTs) and power MOSFET devices can be used to implement the switches. Each device varies in its power ratings and switching speed. IGBTs are well suited for applications that require medium power and switching frequency [13].

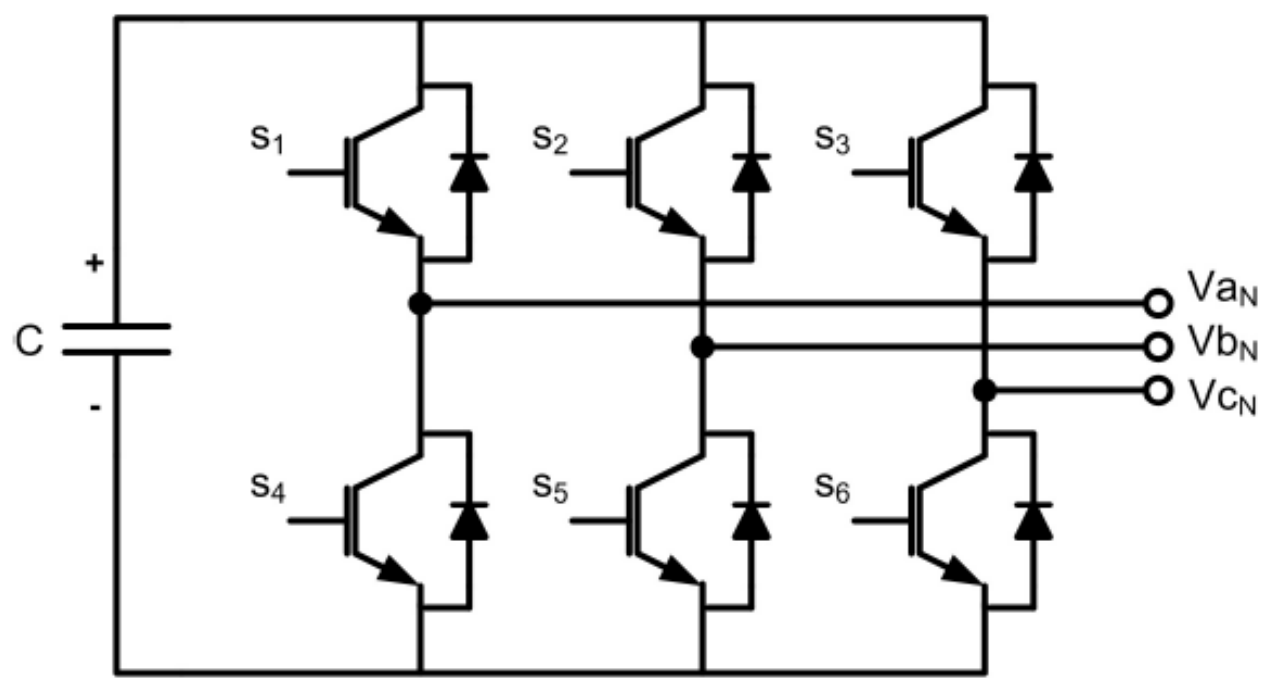

Fig. 2-12: Three-phase voltage source inverter (VSI). 


\subsection{Maximum Power Point Tracking (MPPT) Techniques}

MPPT techniques are used to control DC converters in order to extract maximum output power from a PV array under a given weather condition. The DC converter is continuously controlled to operate the array at its maximum power point despite possible changes in the load impedance. Several techniques have been proposed in literature to perform this task.

\subsubsection{Perturb and Observe}

Perturb and observe algorithm is a simple technique for maximum power point tracking. It is based on controlling the duty cycle $(d)$ of a DC-DC converter to adjust the PV array terminal voltage at the maximum power point [2]. The power output of the array is monitored every cycle and is compared to its value before each perturbation is made. If a change (either positive or negative) in the duty cycle of the DC-DC converter causes output power to increase, the duty cycle is changed in the same direction. If it causes the output power to decrease, then it is reversed to the opposite direction. The algorithm is represented in figure 2-13.

The performance of the algorithm is affected by the choice of the perturbation magnitude $(\Delta d)$ of the converter switching duty cycle. Large perturbations cause large output power fluctuations around the MPP while small perturbations slow down the algorithm. Modifications to this technique are published in [3], [14] and [15] to improve performance while maintaining the basic principle of operation. Table 2-1 illustrates the operation sequence of the algorithm. 


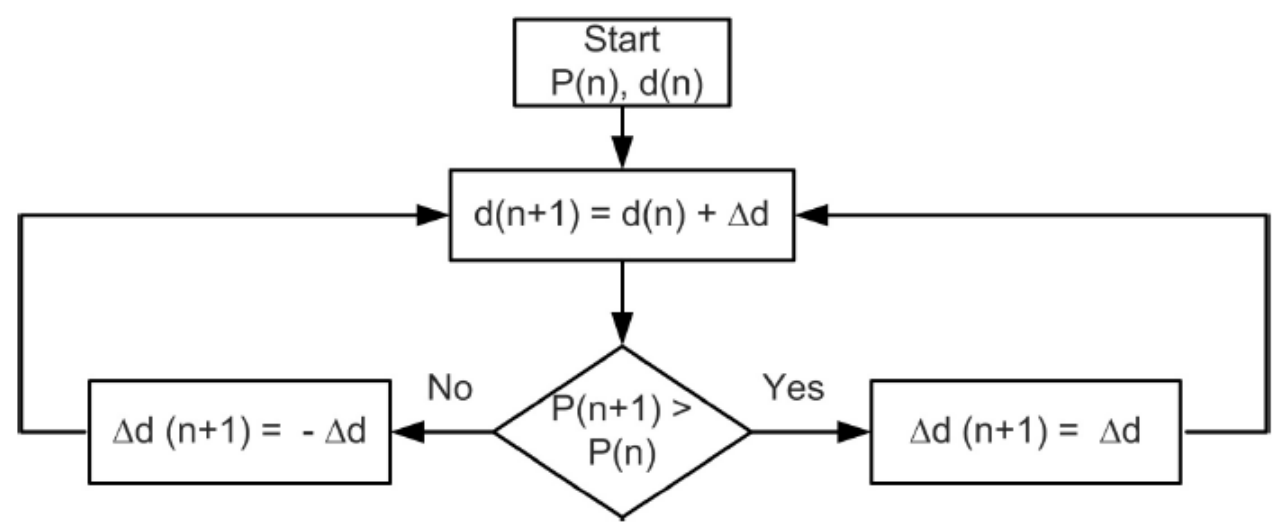

Fig. 2-13: Flowchart of the perturb and observe algorithm.

Table 2-1: Perturbation directions for the P\&O algorithm based on output power variations.

\section{Change in duty cycle, $\Delta d \quad$ Effect on output power}

\section{Next perturbation, $\Delta d(n+1)$}

\begin{tabular}{|c|c|c|}
\hline Increase & Increase & Increase \\
\hline Increase & Decrease & Decrease \\
\hline Decrease & Increase & Decrease \\
\hline Decrease & Decrease & Increase \\
\hline
\end{tabular}

\subsubsection{Incremental Conductance}

This algorithm exploits the fact that the slope of the power-voltage curve of a PV array is equal to zero at the maximum power point, as shown in figure $2-5$. The slope is positive in the area to the left of the maximum power point and negative in the area to the right. Mathematically, this can be summarized as:

$$
\begin{array}{ll}
d P / d V=0, & \text { at } M P P \\
d P / d V>0, & \text { leftof } M P P \\
d P / d V<0, & \text { rightof } M P P
\end{array}
$$

This can be simplified using the following approximation:

$$
d P / d V=d(I V) / d V=I+V d I / d V \approx I+V \Delta I / \Delta V
$$


From that, (2.8) can be rewritten as:

$$
\begin{array}{ll}
\Delta I / \Delta V=-I / V, & \text { at } M P P \\
\Delta I / \Delta V>-I / V, & \text { leftof } M P P \\
\Delta I / \Delta V<-I / V, & \text { rightof } M P P
\end{array}
$$

The incremental conductance algorithm is illustrated in figure 2-14 where $V_{\text {ref }}$ is used as a reference control signal for the DC converter [2], [16], [17]. Similar to the P\&O algorithm, the performance of the incremental conductance MPPT is affected by the increment size of $V_{\text {ref, }}$ used here as the control variable.

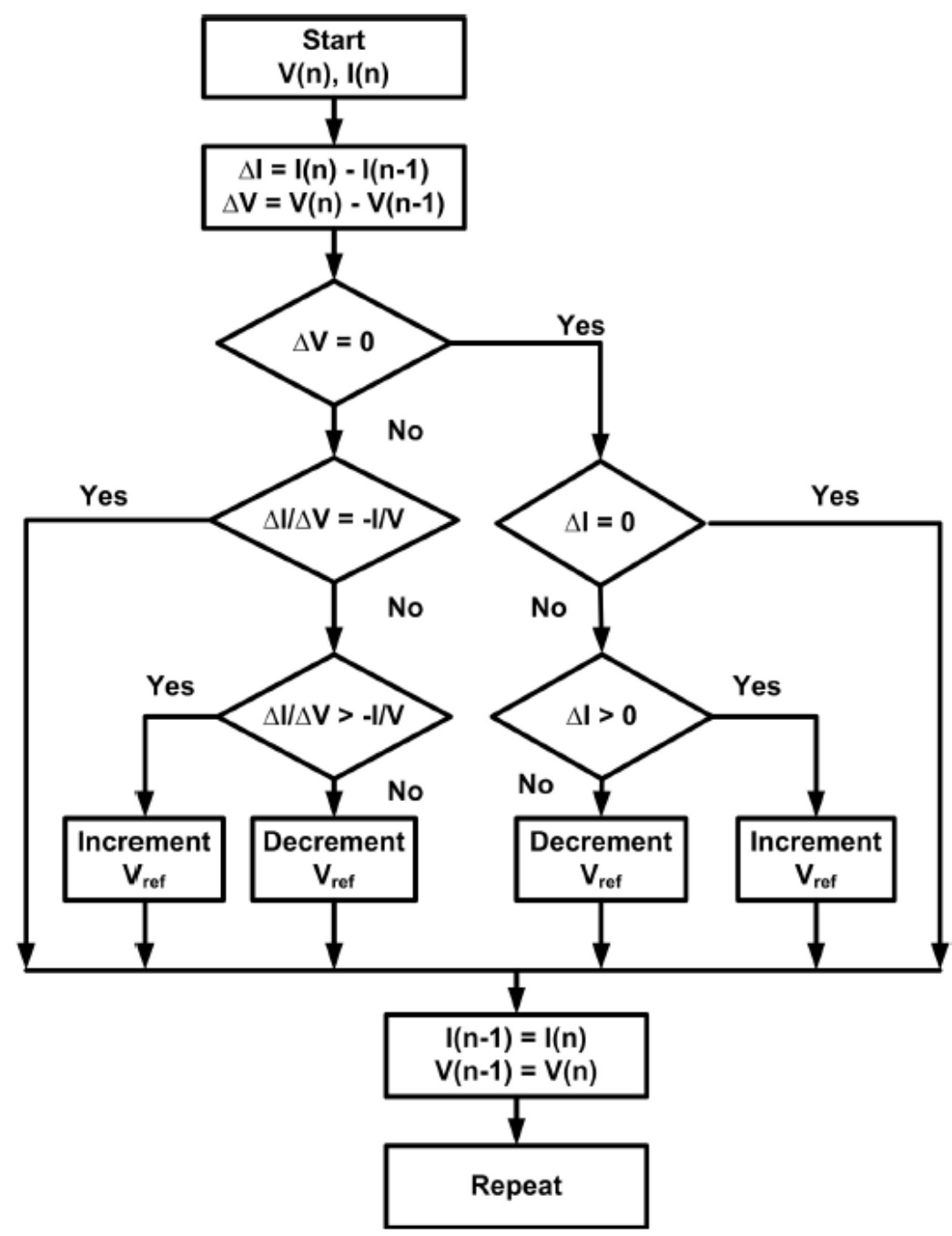

Fig. 2-14: Flowchart of the Incremental conductance MPPT algorithm [2]. 


\subsubsection{Fuzzy Logic-based MPPT}

Fuzzy logic MPPT control is divided into three stages: fuzzification, rule based table look-up and defuzzification. During the fuzzification process, control variable are converted from a numerical value to a linguistic representation like Positive Big $(P B)$, Positive Small $(P S)$, Zero $(Z)$, Negative Small (NS) and Negative Big (NB). The slope of the $P-V$ curve $(S)$ and the change of slope $(\Delta S)$ were used in [18] as the input control variables to the fuzzification stage.

$$
\begin{aligned}
& S=\frac{P(n+1)-P(n)}{V(n+1)-V(n)} \\
& \Delta S=S(n+1)-S(n)
\end{aligned}
$$

where $n$ is the sampling interval, $V$ and $P$ are the terminal voltage and output power of the PV array respectively. Next, a look-up table is used to determine the control action of the converter duty cycle based on the linguistic magnitude of the variables. If the PV array is connected to a boost DC-DC converter, then table 2-2 can be used to issue the control decisions [19]. The look up table is dependent on the DC converter topology being used. Since the control command is also in linguistic format, it should be first converted to a numerical value during the defuzzification stage. When both the slope and change of slope variables reach zero, the maximum power point is reached.

Fuzzy logic controllers can perform maximum power point tracking effectively under changing weather conditions. However, there is some difficulty designing the look up table and the rules that govern the operation of the controller for different converter topologies. In addition, thresholds that define the linguistic variables are to be carefully selected because they can impact the algorithm performance. An adaptive fuzzy logic controller was proposed in [20] to dynamically tune these thresholds to achieve improved performance. 
Table 2-2: Rule based look-up table for fuzzy logic MPPT [19].

\begin{tabular}{|c|c|c|c|c|c|}
\hline$s \Delta$ & NB & NS & $Z$ & $P S$ & $P B$ \\
\hline$N B$ & Z & $Z$ & NB & NB & NB \\
\hline NS & Z & $Z$ & NS & NS & NS \\
\hline Z & NS & $Z$ & $Z$ & $Z$ & PS \\
\hline$P S$ & PS & PS & $\mathrm{PS}$ & $Z$ & $Z$ \\
\hline$P B$ & PB & PB & PB & $Z$ & Z \\
\hline
\end{tabular}

\subsubsection{Neural Networks}

Neural networks based MPPT is one of the techniques suited for implementation using microcontrollers [21], [22]. A neural network is composed of three layers: the input, hidden and output layers. Inputs to a network can be the array terminal voltage and the solar irradiation level or any other measurements needed by the MPPT algorithm. Each node in the network is referred to as a neuron; these neurons are connected together through lines that are associated with certain weighted sums $w_{i j}$. The effectiveness of this MPPT technique is mainly determined by the hidden layer and the amount of training the network received. The training process might span several months or years where the network is subjected to various measurements obtained from the PV system. Using this information, the weights between the neurons are tuned to generate the required output which could be a command to change a DC converter duty cycle. A disadvantage of this technique is the lengthy training process it needs before the neural network can accurately track the maximum power point, in addition to its dependency on the characteristics of the PV array to which it is connected. 


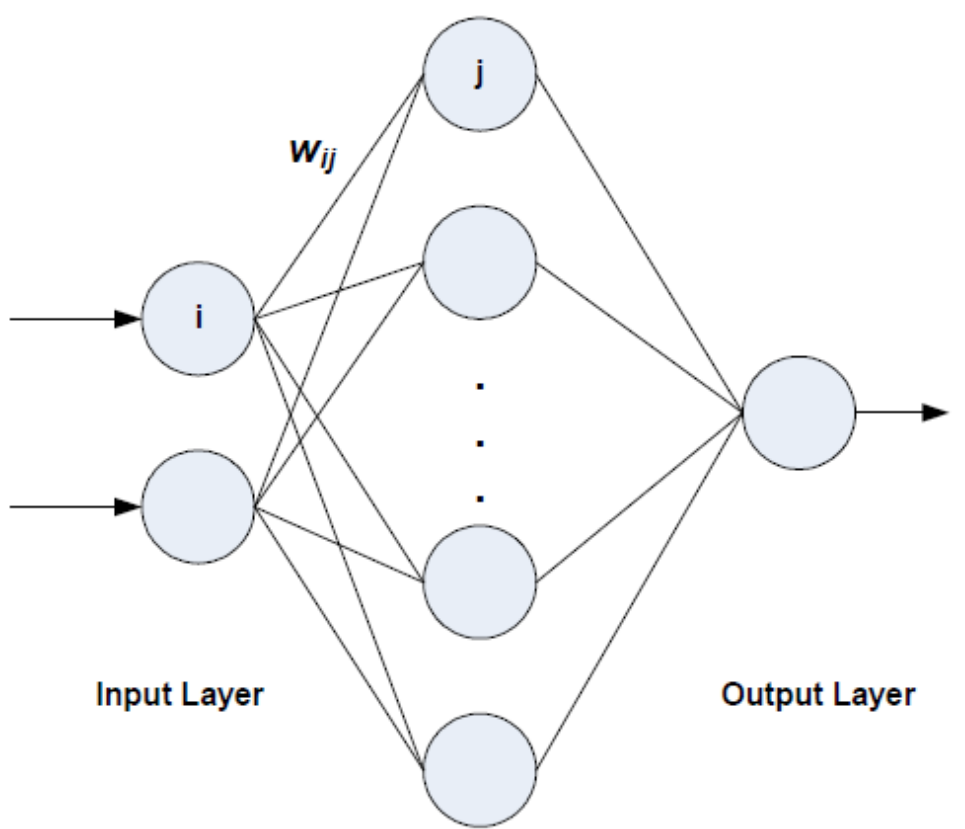

Hidden Layer

Fig. 2-15: Neural network for MPPT control. 


\section{Chapter 3 \\ Control of Three-Phase Grid Connected PV System}

This chapter covers the control system developed to operate a grid-connected PV system. First, an introduction to support vector regression theory is introduced. Second, the proposed control of the boost DC-DC converter is explained where support vector regression based multi-stage algorithm is adopted in order to track the maximum power point for the PV system. Then, an overview of controlling the grid interfacing inverter is provided.

\subsection{Support Vector Regression Theory}

The idea of the support vector regression technique is based on computation of the linear regression function in a high dimensional feature space $\Phi$ where the input data $\mathrm{x}$ are mapped using some nonlinear function. Thus, the SVR problem can be defined as the determination of function $f(x)$ which approximates an unknown desired function and has the following form [23]

$$
f(x)=(w . \Phi(x))+b
$$

where (.) denotes the inner product, $w \subset R^{n}, b \subset R$, and $\Phi$ denotes a non-linear transformation from $R^{n}$ space to high dimensional space (see Fig. 3-1). Considering a set of training data $\left.\left(x_{i}, y_{i}\right)\right|_{i=1} ^{n}, i=1, \ldots, n$ where $x_{i} \subset R^{n}$ denotes the input space of the sample and has a corresponding target value $y_{i} \subset R$, and $n$ is the dimension of the training data. To calculate the parameter vector $w$, the following cost function should be minimized [23], [24]:

$$
\operatorname{Min} \frac{1}{2}\|w\|^{2}+C \sum_{i=1}^{n} \Gamma\left(f\left(x_{i}\right)-y_{i}\right)
$$

subject to 

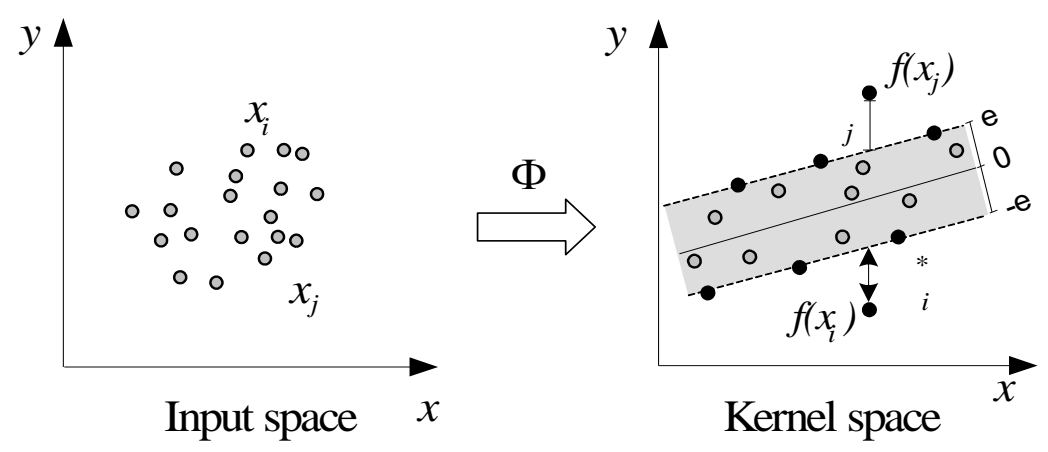

Fig. 3-1: Data transformation from input space to kernel space.

$$
\left|y_{i}-w \cdot \Phi\left(x_{i}\right)-b\right| \leq \varepsilon+\zeta_{i}, \quad i=1,2, . ., n \quad \zeta_{i}, \zeta_{i}^{*} \geq 0
$$

where $\Gamma(\cdot)$ is a cost function, $\varepsilon$ is the permissible error, and $C$ is a pre-specified value that controls the cost incurred by training errors. Every vector outside $\varepsilon$-tube is captured in slack variables $\zeta_{i}, \zeta_{i}^{*}$, which are introduced to accommodate unpredictable errors on the input training set.

The constraints include the term, $\varepsilon$, which allows a margin of error without incurring any cost. The value of $\varepsilon$ can affect the number of support vectors used to construct the regression function. As $\varepsilon$ is larger, the support vectors selected are fewer. Hence, vales of $\varepsilon$ affect the model complexity. With reasonable choice of $C$, a tradeoff between minimizing training errors and minimizing the model complexity term $\|w\|^{2}$ is accomplished.

The key idea to satisfy these constraints is to construct a Lagrange function from the objective function and the corresponding constraints by including the linear restrictions (3.3) into (3.2) using Lagrange multipliers $\alpha_{i}, \alpha_{i}^{*}$ associated to each sample as 


$$
\begin{aligned}
L= & \frac{1}{2}\|w\|^{2}+C \sum_{i=1}^{n} \Gamma\left(f\left(x_{i}\right)-y_{i}\right) \\
& +\sum_{i} \alpha_{i}\left(y_{i}-w \cdot \Phi\left(x_{i}\right)-b-\varepsilon-\zeta_{i}\right) \\
& +\sum_{i} \alpha_{i}\left(-y_{i}+w \cdot \Phi\left(x_{i}\right)+b-\varepsilon-\zeta_{i}^{*}\right)
\end{aligned}
$$

which is subject to $\alpha_{i}, \alpha_{i}^{*}, \zeta_{i}, \zeta_{i}^{*}>0$. Now (3.4) has to be minimized with regard to primal variables $\left(w, b\right.$, and $\left.\zeta_{i}, \zeta_{i}^{*}\right)$ and maximized with regard to the Lagrange multipliers $\alpha_{i}, \alpha_{i}^{*}$. Therefore, by making zero the gradient of $L$ with respect to the primal variables, we obtain the following conditions

$$
\begin{aligned}
& \frac{\partial L}{\partial w}=0 \rightarrow w=\sum_{i}\left(\alpha_{i}-\alpha_{i}^{*}\right) \Phi\left(x_{i}\right) \\
& \frac{\partial L}{\partial b}=0 \rightarrow \sum\left(\alpha_{i}-\alpha_{i}^{*}\right)=0 \\
& \frac{\partial L}{\partial \zeta_{i}^{*}}=0 \rightarrow C=\zeta_{i}^{*} \\
& \frac{\partial L}{\partial \zeta_{i}}=0 \rightarrow C=\zeta_{i}
\end{aligned}
$$

If constraints (3.5)-(3.7) are included in the Lagrange functional (3.4), the optimization problem is then obtained as

$$
\begin{array}{r}
\operatorname{Max}-\frac{1}{2} \sum_{i, j=1}^{n}\left(\alpha_{i}-\alpha_{i}^{*}\right)\left(\alpha_{j}-\alpha_{j}^{*}\right) K\left(x_{i}-x_{j}\right) \\
+\sum_{i=1}^{n} y_{i}\left(\alpha_{i}-\alpha_{i}^{*}\right)-\varepsilon \sum_{i=1}^{n}\left(\alpha_{i}+\alpha_{i}^{*}\right)
\end{array}
$$

subject to

$$
\sum_{i=1}^{n}\left(\alpha_{i}-\alpha_{i}^{*}\right)=0, \alpha_{i}, \alpha_{i}^{*} \in[0, C]
$$

where $K$ represents the kernel matrix 


$$
K\left(x_{i}, x\right)=\Phi(x) \cdot \Phi\left(x_{i}\right)
$$

Equation (3.1) can be transformed into the final solution as

$$
f(x)=\sum_{i=1}^{n}\left(\alpha_{i}-\alpha_{i}^{*}\right) \cdot K\left(x_{i}-x\right)+b
$$

subject to

$$
0 \leq \alpha_{i} \leq C, 0 \leq \alpha_{i}^{*} \leq C
$$

where only the training examples whose corresponding Lagrange multipliers are nonzero are involved in the solution, which are called support vectors.

Several choices for the kernel are possible to reflect special properties of approximating functions; the radial base function $(\mathrm{RBF})$ is used in this work:

$$
K\left(x_{i}, x\right)=\exp \left\{-\frac{\left|x_{i}, x\right|^{2}}{\sigma^{2}}\right\}
$$

where the $\sigma$ is called as kernel parameter. Fig. 3-2 shows the schematic diagram of the SVR.

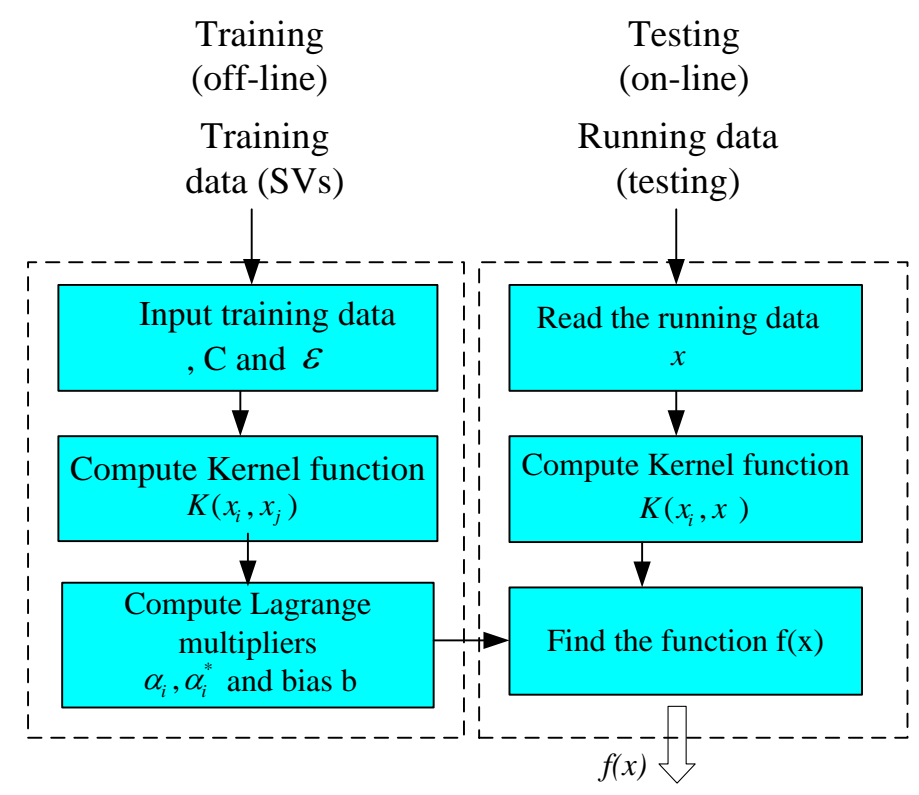

Fig. 3-2: Schematic Diagram of the SVR. 


\subsection{Proposed SVR Based Algorithm (MSA)}

As mentioned earlier, the output power of the PV system depends on the solar insolation $(G)$ and temperature $(\mathrm{T})$. Figure 3-3 shows $I-V$ characteristics for a $\mathrm{PV}$ array under variable irradiation and temperature. The figure can be divided into two zones: zone A on the left side where curves do not intersect with each other, and zone B on the right side where curves intersect with each other in several points. If the SVR is used to estimate the irradiation and temperature at the intersecting points on the right side, the performance of the estimator will be deteriorated. Therefore, we propose a multi-stage SVR based algorithm to solve the aforementioned problem.

The proposed algorithm consists of three stages: The first stage estimates the initial values of temperature and irradiation; the second stage instantaneously estimates the irradiation assuming that the temperature is constant within a one-hour time span; and the third stage updates the estimated temperature once every one hour.

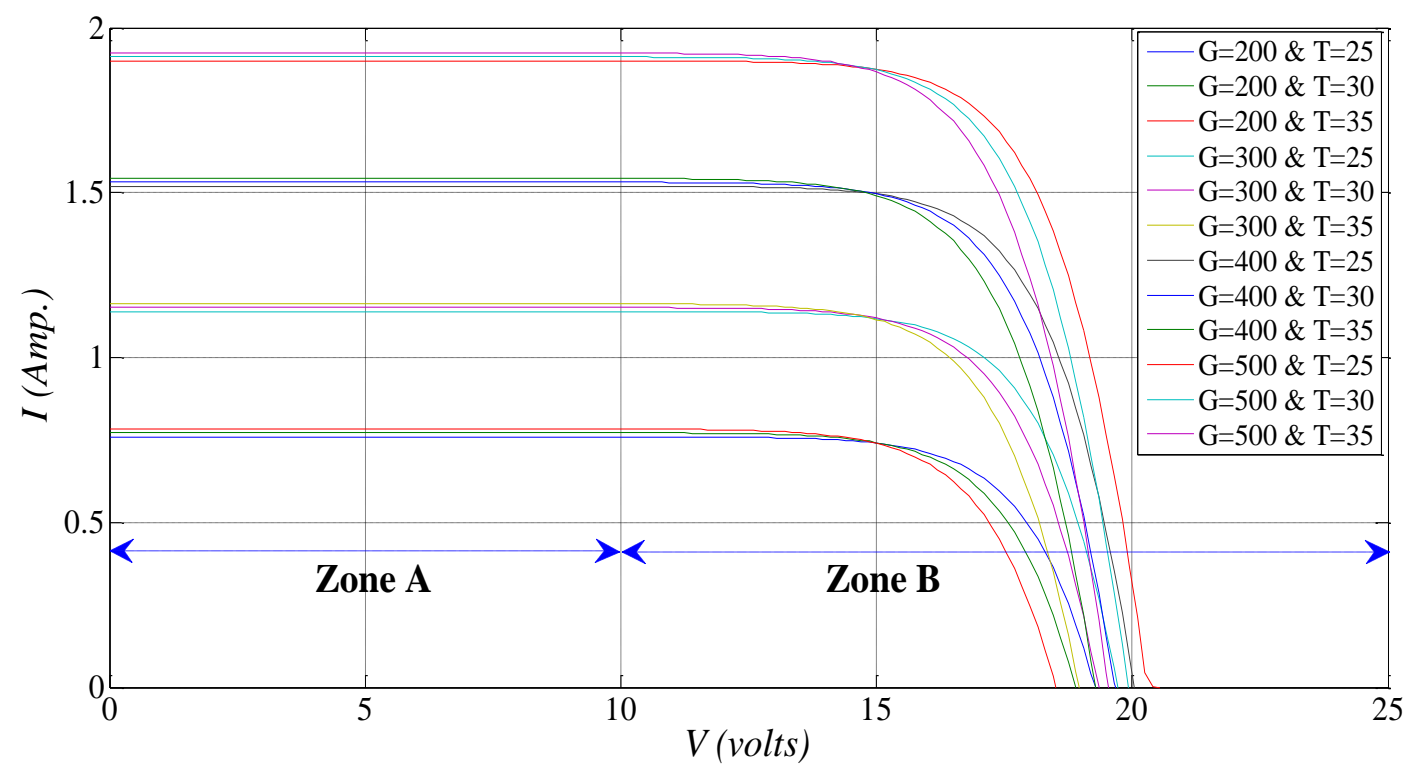

Fig. 3-3: $I-V$ curves for $P V$ under variable irradiation $(G)$ in $W / m^{2}$ and temperature $(T)$ in ${ }^{\circ} \mathrm{C}$. 
The proposed MSA is composed of three SVR modules (SVR1, SVR2, and SVR3). SVR1 estimates the temperature $(T)$ as a function of the voltage and current; the training samples for SVR1 are taken from zone A; SVR1 is only used when the reference voltage of the boost converter controller $V_{\text {ref }}$ is set to equal $V_{\text {selected }}$ which is a voltage exists in zone A, its selection is left to the designer. SVR2 estimates the irradiation $(G)$ as a function of the voltage, current, and temperature; the training samples for SVR2 are taken from zones A and B assuming that the temperature is constant within a one hour time span. SVR3 module estimates the voltage corresponding to the MPP $\left(V_{m p}\right)$ as a function of the irradiation and temperature. Then, $V_{r e f}$ is set to equal $V_{m p}$. Every one hour, the reference voltage is set to equal $V_{\text {selected }}$, and SVR1 updates the temperature. Fig. 3-4 shows the flow chart of the proposed MSA, and Fig. 3-5 shows the power circuit and control circuit of the DCDC boost converter. The control of the grid-interfacing inverter is explained in the nest session. 


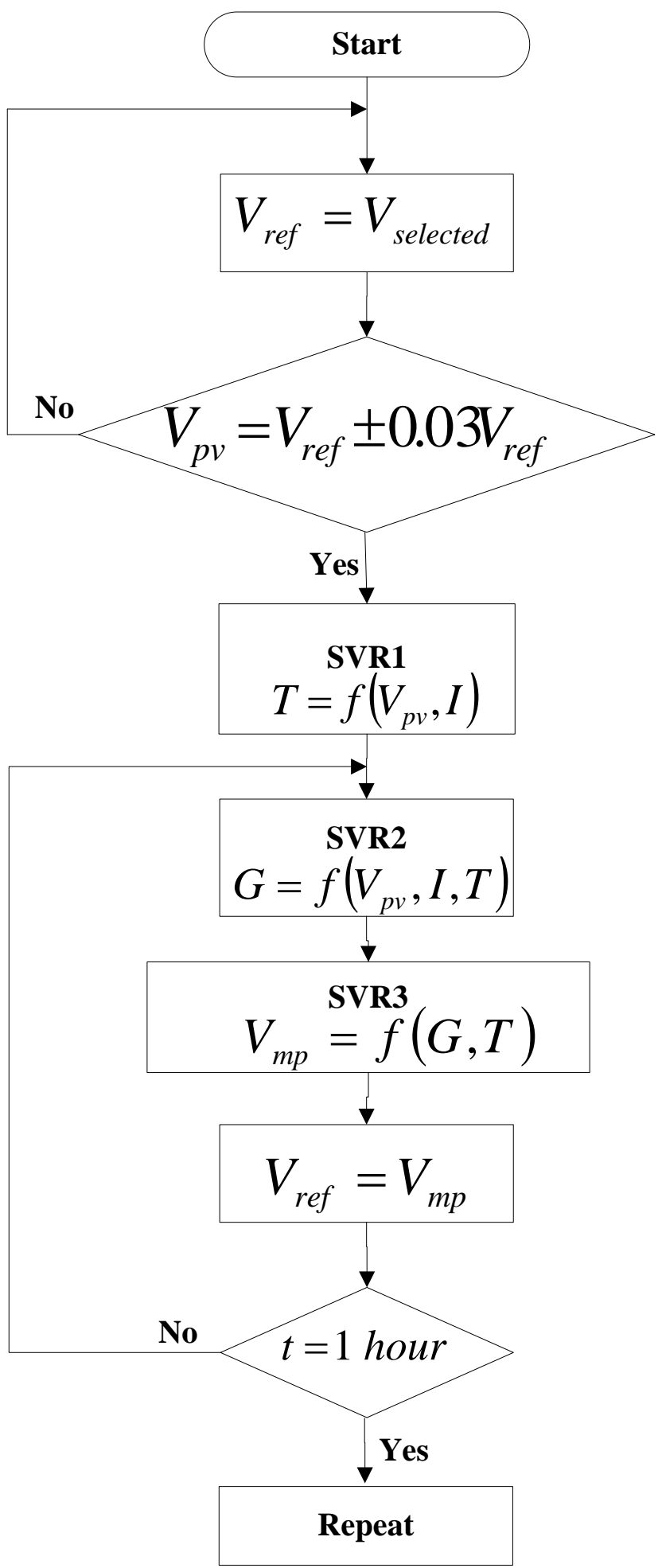

Fig. 3-4: The flow chart of the proposed MSA. 


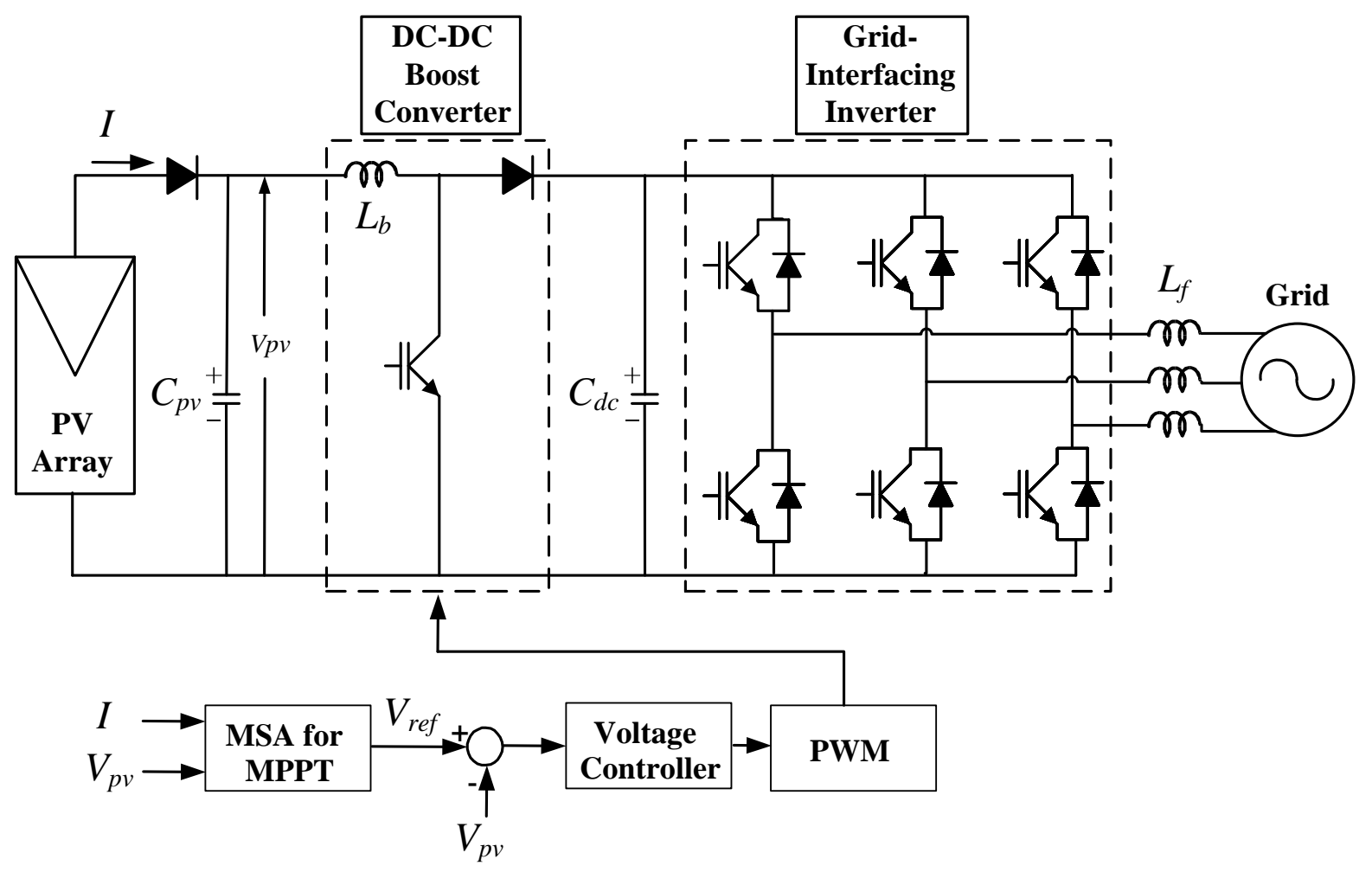

Fig. 3-5: The power and control circuit for the DC-DC boost converter.

\subsection{Control of Grid-Interfacing Inverter}

To achieve the full control of the grid-side current, the dc-link voltage must be boosted to a level higher than the amplitude of the line-line voltage. The power flow of the grid-side converter is controlled so as to keep the dc-link voltage constant. To maintain the dc-link voltage constant and to ensure the reactive power flowing into the grid at null, the grid-side converter currents are controlled using the $d$ - $q$ vector control approach. The dc-link voltage is controlled to the desired value by using an IP controller and the change in the DC-link voltage represents a change in the $q$-axis current. A simple voltage control scheme is shown in Fig. 3-6. A current feed-forward control loop is also used here to improve the dc-link voltage response to load disturbance. For unity power factor, the demand for the $d$-axis current is zero. Fig. 3-7 shows a control block diagram of the grid-interfacing inverter. 


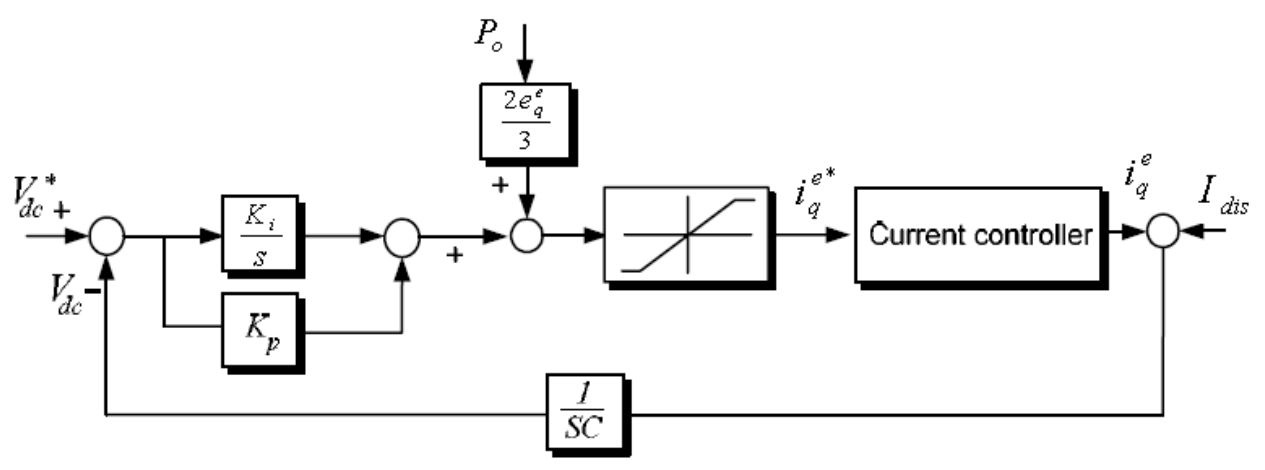

Fig. 3-6: Voltage controller block diagram.

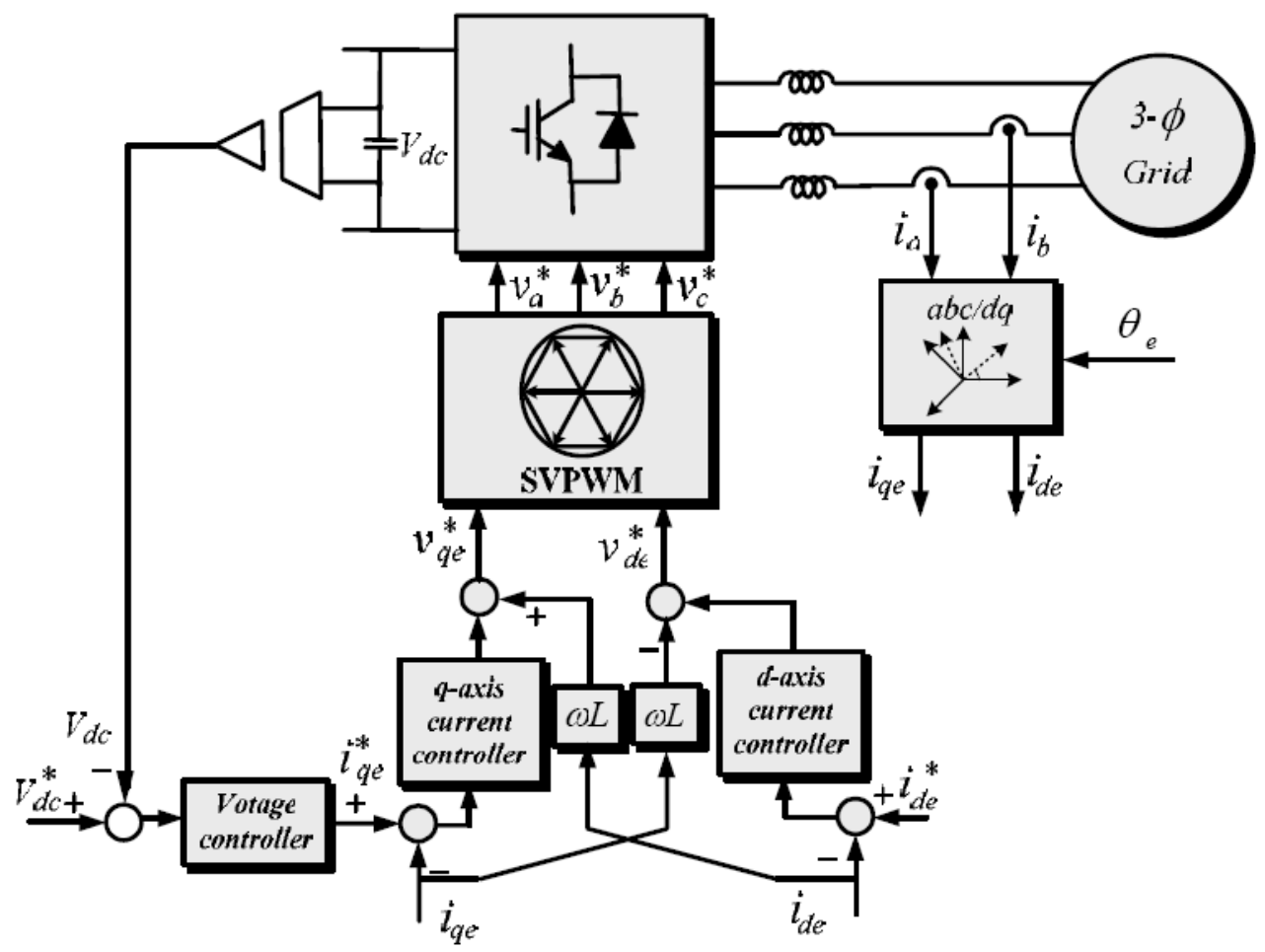

Fig. 3-7: Grid-interfacing inverter control. 


\section{Chapter 4 Simulation Results}

To verify the effectiveness of the proposed MSA, PSCAD/EMTDC simulations (interfaced with Matlab) have been performed for different temperatures and irradiation levels, where the schematic diagram of the implemented system was shown in Fig. 3-5.

Figs. 4-1, 4-2, and 4-3 show that the proposed MSA can estimate perfectly the initial temperature values 25,30 , and $35^{\circ} \mathrm{C}$, respectively. For each temperature, the irradiation levels are 200, 300, 400, and $500 \mathrm{~W} / \mathrm{m}^{2}$. First, the reference voltage $V_{\text {ref }}$ is set to equal $V_{\text {selected, }}$, which equals 9 volts, while SVR1 is activated to estimate the temperature. Then, the temperature value is kept constant at its last estimated value before $t=0.015 \mathrm{sec}$ when $V_{p v}$ equals $V_{\text {ref }}$. After $t=0.015 \mathrm{sec}$, SVR3 is activated to estimate the voltage $V_{m p}$ corresponding to the maximum power, and $V_{\text {ref }}$ is set to equal $V_{m p}$. The Figures also show that the proposed MSA can estimate the irradiation level and track the MPP with a high accuracy. 


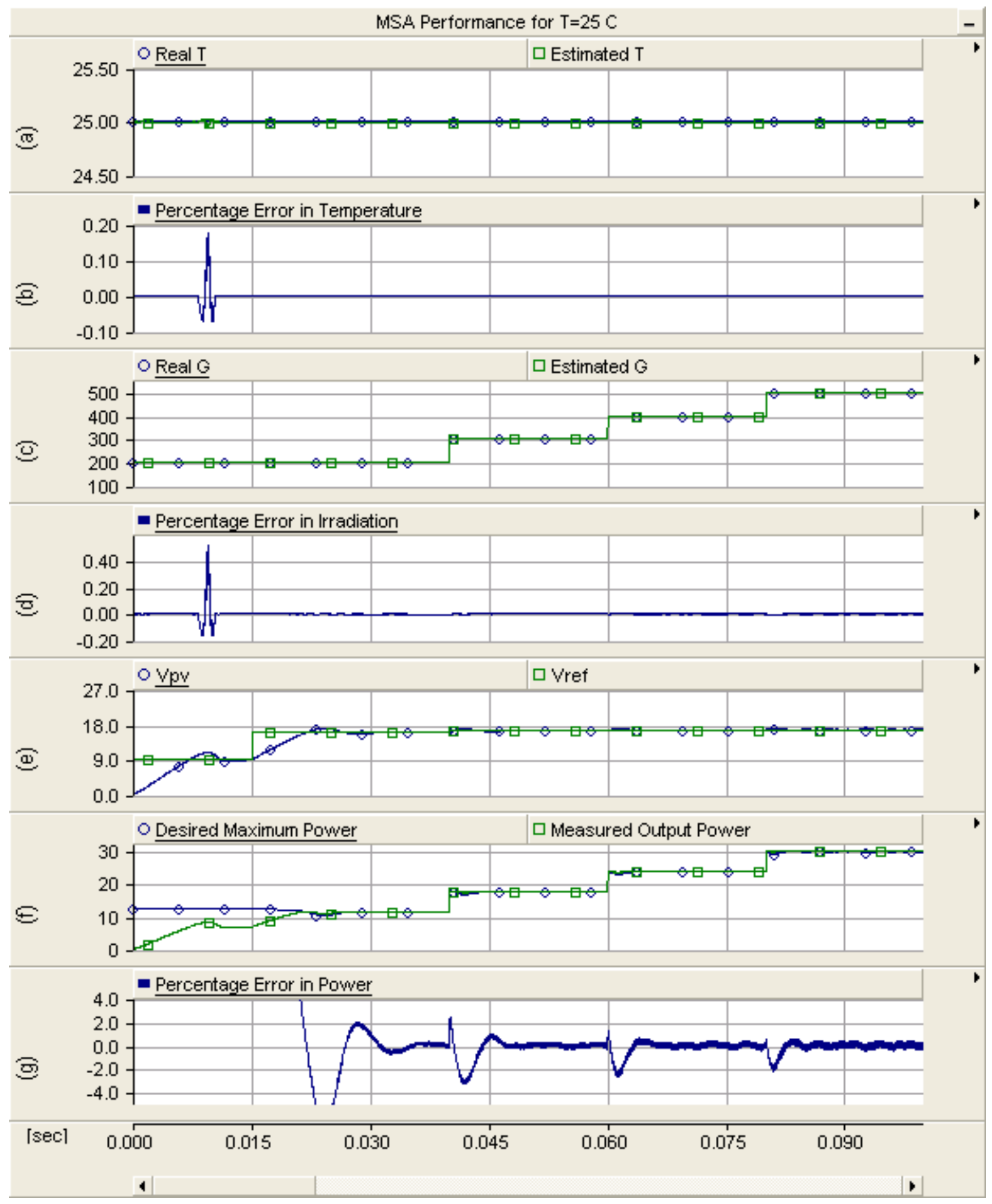

Fig. 4-1: MSA performance for $\mathrm{T}=25^{\circ} \mathrm{C}$. 


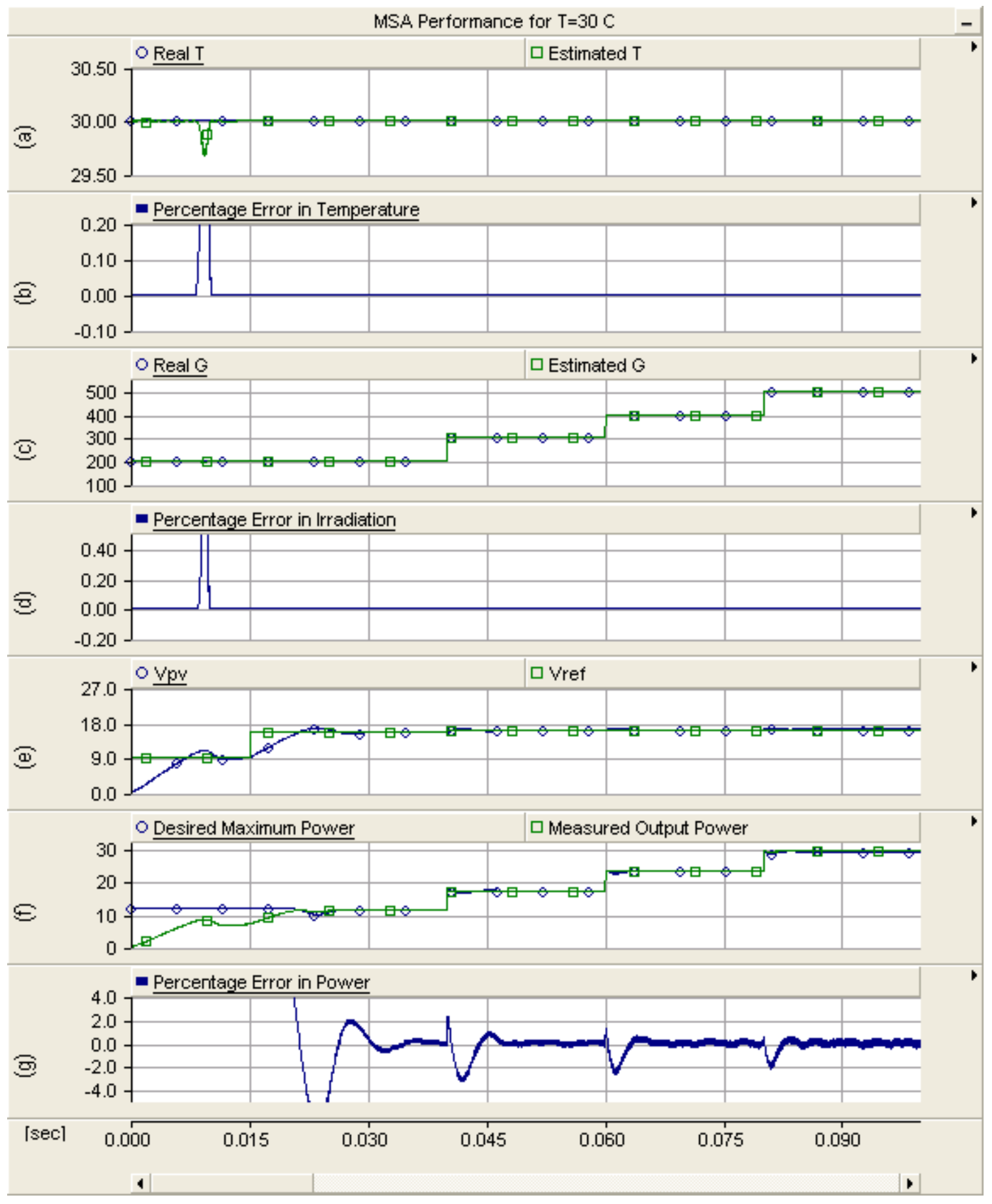

Fig. 4-2: MSA performance for $\mathrm{T}=30^{\circ} \mathrm{C}$. 


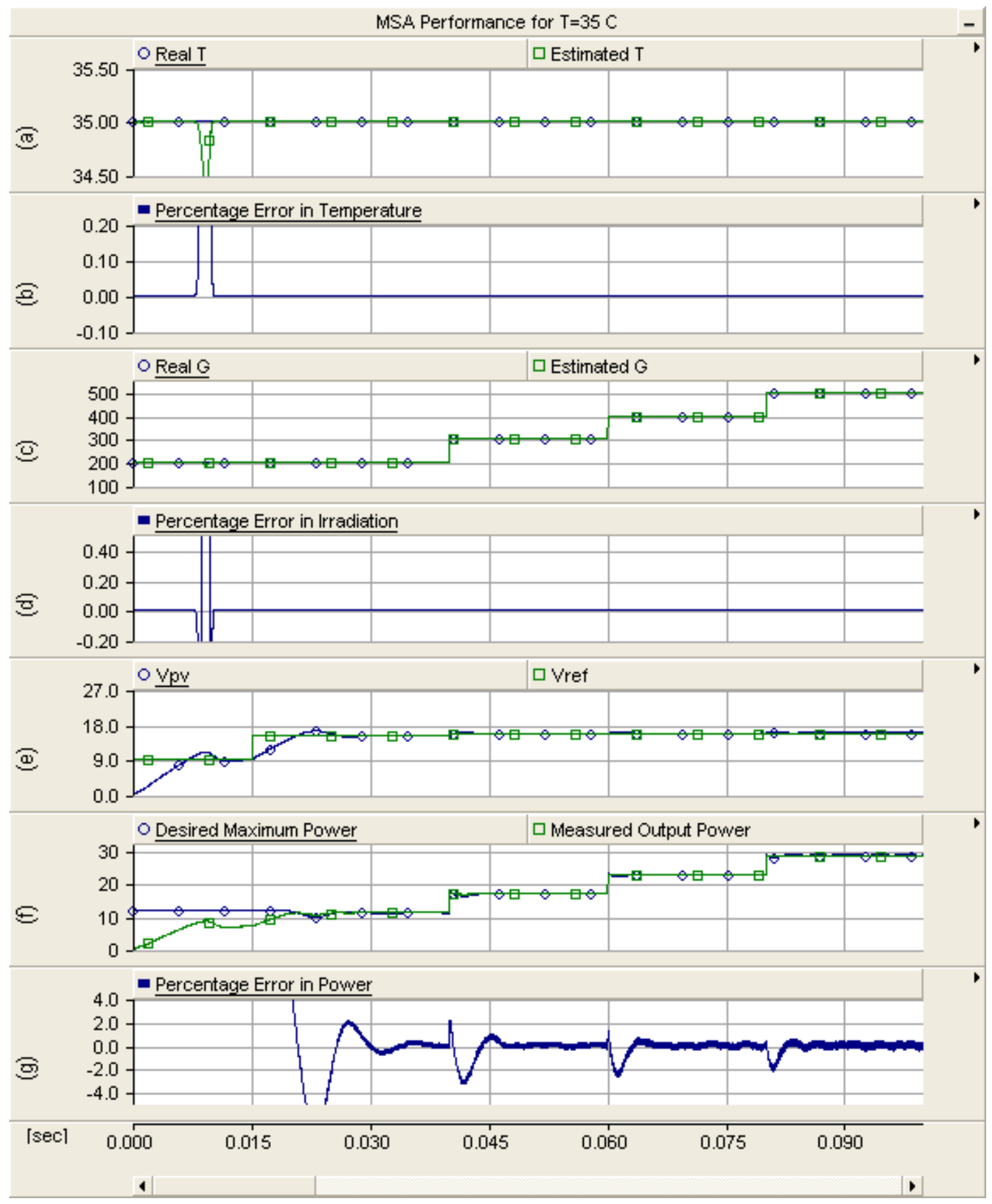

Fig. 4-3: MSA performance for $\mathrm{T}=35^{\circ} \mathrm{C}$. 
Fig. 4-4 shows the response of the proposed MSA to a step change in the temperature. At $t=0.15$ sec, the temperature changed from 25 to $35{ }^{\circ} \mathrm{C}$. As a consequence, the percentage error for both irradiation level and output power is increased to approximately 5.2. At $t=0.207 \mathrm{sec}, V_{\text {ref }}$ is set to equal $V_{\text {selected, }}$, and SVR1 is activated to update the temperature accurately. As a result, the percentage error for both irradiation level and output power is decreased again to almost zero. 


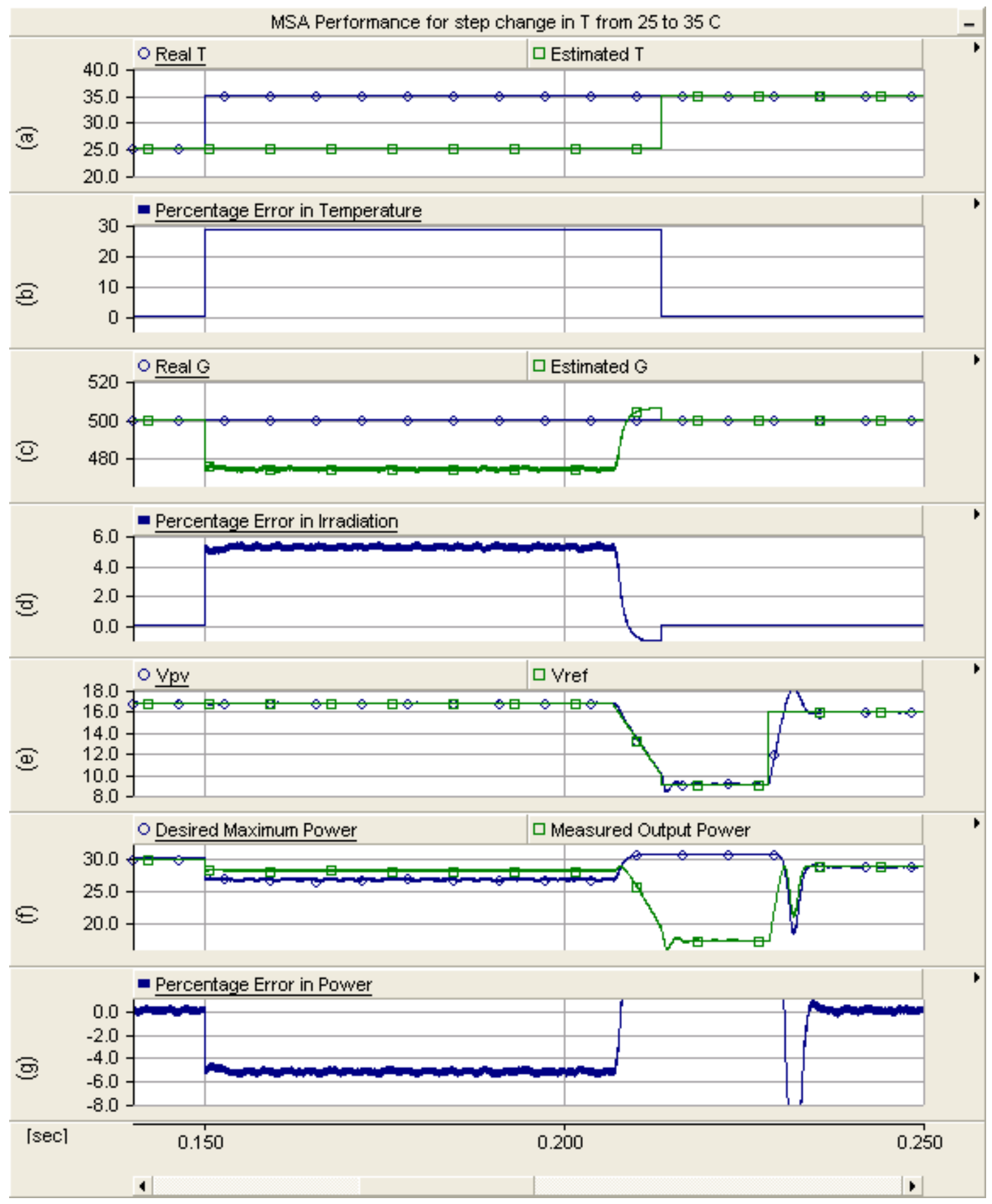

Fig. 4-4: MSA performance for step change in $\mathrm{T}$ from 25 to $35{ }^{\circ} \mathrm{C}$. 


\section{Chapter 5}

\section{Conclusion and Future Work}

\subsection{Conclusion}

In this thesis, a novel senseless SVR based multi-stage algorithm (MSA) for MPPT in PV systems is proposed. The proposed algorithm avoids using outdoor irradiation and temperature sensors which means lower cost. Moreover, it improves the reliability of the system based on the fact "using less number of sensors improves the reliability of the system." The proposed MSA consists of three stages: The first stage estimates the initial values of irradiation and temperature; the second stage instantaneously estimates the irradiation with the assumption that the temperature is constant over one-hour time intervals; the third stage updates the estimated value of the temperature once every one hour. After estimating the irradiation and temperature, the voltage corresponding to the MPP is estimated, as well. Then, the reference PV voltage is given to the power electronics interface. The proposed strategy is robust to rapid changes in solar irradiation and load, and it is also insensitive to ambient temperature variations. Simulations studies in PSCAD/EMTDC and Matlab demonstrate the effectiveness of the proposed technique.

\subsection{Future Work}

As a future work, incorporation of the partial shading effect of PV arrays can be carried on to expand the scope of this research. This problem arises when sunlight is blocked from hitting a section of a PV array directly while other sections continue their normal operation. The estimation process of the irradiation and temperature of the PV array will not be accurate and this will cause significant deviations from the maximum power point. The control system should be able to detect this situation 
and carry out any required corrections. This control requirement should be carried on close to real time in order to avoid any delays that would degrade the dynamic response of the algorithm. 


\section{References}

[1] Natural Resources Canada, "Photovoltaic Systems Introduction," [Online].

Available: http://www.energyalternatives.ca/PDF/Photovoltaic Systems Introduction.pdf

[2] T. Esram and P. L. Chapman, "Comparison of Photovoltaic Array Maximum Power Point Tracking Techniques," IEEE Transactions on Energy Conversion, vol. 22, pp. 439-449, 2007.

[3] N. Femia, G. Petrone, G. Spagnuolo, and M. Vitelli, "Optimization of perturb and observe maximum power point tracking method," IEEE Transactions on Power Electronics, vol.20, no.4, pp. 963-973, July 2005.

[4] Byunggyu Yu; A.G. Abo-Khalil, Junghun So, and Gwonjong Yu, "Support vector regression based maximum power point tracking for PV grid-connected system," in Proc. IEEE Photovoltaic Specialists Conference (PVSC), Philadelphia, PA, June 2009, pp. 2037-2042.

[5] Masters, Gilbert M., Renewable and efficient electric power systems. John Wiley \& Sons, 2004.

[6] J.A. Gow and C. Manning, "Development of a photovoltaic array model for use in powerelectronics simulation studies," in Proc. IEE Electric power applications, vol. 146, no. 2, pp.193-200, March 1999.

[7] US Department of Energy (DOE). (2010). Solar Energy Technologies Program. [Online]. Available: http://www1.eere.energy.gov/solar/pv devices.html

[8] International Energy Agency (IEA)-PVPS. (2009, Sept.). Trends in photovoltaic applications. [Online]. Available: www.iea-pvps.org

[9] M. G. Villalva, et al., "Comprehensive Approach to Modeling and Simulation of Photovoltaic Arrays," IEEE Transactions on Power Electronics, vol. 24, pp. 1198-1208, 2009.

[10] S. B. Kjaer, J. K. Pedersen, and F. Blaabjerg, "A review of single-phase grid-connected inverters for photovoltaic modules,” IEEE Trans. Ind. Appl., vol. 41, no. 5, pp. 1292-1306, Sep./Oct. 2005. 
[11] I. Atlas and A. Sharaf "A photovoltaic array simulation model for Matlab Simulink GUI environment," in international Conf. on Clean Electrical Power, pp.341-345, May 2007.

[12] Shengyi Liu and R.A. Dougal, "Dynamic multiphysics model for solar array," IEEE Transactions on Energy Conversion, vol.17, no.2, pp.285-294, Jun 2002.

[13] Bin Wu, High-Power Converters and AC Drives. John Wiley \& Sons, 2006.

[14] Weidong Xiao and Dunford, "A modified adaptive hill climbing MPPT method for photovoltaic power systems," 35th IEEE Annual Power Electronics Specialists Conference. PESC 04. vol. 3, no., pp. 1957- 1963 Vol.3, 20-25 June 2004.

[15] N.S. D'Souza, Lopes, L. A. C., and Xuejun Liu, "An Intelligent Maximum Power Point Tracker Using Peak Current Control," 36th IEEE Power Electronics Specialists Conference, June 2005.

[16] K.H. Hussein, I. Muta, T. Hoshino, and M. Osakada, "Maximum photovoltaic power tracking: an algorithm for rapidly changing atmospheric conditions," IEE Proceedings on Generation, Transmission and Distribution, vol.142, no.1, pp.59-64, Jan 1995.

[17] Tae-Yeop Kim, Ho-Gyun Ahn, Seung Kyu Park, and Youn-Kyun Lee, "A novel maximum power point tracking control for photovoltaic power system under rapidly changing solar radiation," IEEE International Symposium on Industrial Electronics., vol.2, no., pp.1011-1014 vol.2, 2001.

[18] N. Khaehintung, K. Pramotung, B. Tuvirat, and P. Sirisuk, "RISC-microcontroller built-in fuzzy logic controller of maximum power point tracking for solar-powered light-flasher applications," in Proc. IECON 2004, vol.3, no., pp. 2673- 2678 Vol. 3, 2-6 Nov. 2004.

[19] Chung-Yuen Won, Duk-Heon Kim, Sei-Chan Kim, Won-Sam Kim, and Hack-Sung Kim, "A new maximum power point tracker of photovoltaic arrays using fuzzy controller," ., 25th Annual IEEE Power Electronics Specialists Conference, PESC '94, pp.396-403 vol.1, 20-25 Jun 1994. 
[20] N. Patcharaprakiti and S. Premrudeepreechacharn, "Maximum power point tracking using adaptive fuzzy logic control for grid-connected photovoltaic system," IEEE Power Engineering Society Winter Meeting, vol.1, no., pp. 372- 377 vol.1, 2002.

[21] L. Zhang, Yunfei Bai, and A. Al-Amoudi, "GA-RBF neural network based maximum power point tracking for grid-connected photovoltaic systems," International Conference on Power Electronics, Machines and Drives, vol., no., pp. 18- 23, 4-8 June 2002.

[22] T. Hiyama and S. Kouzuma, T. Imakubo, "Identification of optimal operating point of PV modules using neural network for real time maximum power tracking control," IEEE Transactions on Energy Conversion, vol.10, no.2, pp.360-367, Jun 1995.

[23] A. J. Smola and B. Schölkopf, “A tutorial on support vector regression,” Statist. Comput., vol. 14, pp. 199-222, 2004.

[24] K. R. Muller, A. Smola, G. Ratsch, B. Scholkopf, J. Kohlmorgen, and V. Vapnik, "Predicting time series with support vector machines," in Proc. ICANN. New York: Springer-Verlag, 1997, vol. 1327, pp. 999-1004. 


\section{Appendix A}

\section{System Data}

TYPICAL ELECTRICAL CHARACTERISTIC OF MSX-60 PV MODULE.

\begin{tabular}{lcc}
\hline \hline Parameter & Variable & Value \\
\hline Maximum Power & $P_{m}$ & $60 \mathrm{~W}$ \\
Voltage@P $P_{m}$ & $V_{m}$ & $17.1 \mathrm{~V}$ \\
Current @ $P_{m}$ & $I_{m}$ & $3.5 \mathrm{~A}$ \\
Short circuit current & $I_{S C}$ & $3.8 \mathrm{~A}$ \\
Open-circuit voltage & $V_{O C}$ & $21.1 . \mathrm{V}$ \\
Temperature coefficient of open- & $\beta$ & $-(80 \pm 10) \mathrm{mV} /{ }^{\circ} \mathrm{C}$ \\
circuit voltage & & \\
Temperature coefficient of short- & $\alpha$ & $(0.0065 \pm 0.015) \% /{ }^{\circ} \mathrm{C}$ \\
circuit current & & \\
Temperature coefficient of power & & $-(0.5 \pm 0.05) \% /{ }^{\circ} \mathrm{C}$ \\
NOCT &
\end{tabular}

\begin{tabular}{|c|c|}
\hline Parameters in Fig. 3-5 & Value \\
\hline$C_{p v}$ & $500[\mu \mathrm{F}]$ \\
\hline$L_{b}$ & $0.001[\mathrm{H}]$ \\
\hline$C_{d c}$ & $2000[\mu \mathrm{F}]$ \\
\hline$L_{f}$ & $0.001[\mathrm{H}]$ \\
\hline$V_{L-G}$ & $208[\mathrm{~V}]$ \\
\hline$f$ & $60[\mathrm{Hertz}]$ \\
\hline
\end{tabular}

